\title{
Hierarquia e concentração na distribuição regional brasileira de invenções por tipos de tecnologias*
}

\author{
Rodrigo Siqueira Rodriguez ${ }^{* *}$ \\ Eduardo Gonçalves ${ }^{* * *}$
}

Recebido: 03/06/2016 Versão Revisada (entregue): 23/09/2016 Aprovado: 26/10/2016

\section{RESUMO}

Este artigo propõe uma classificação das regiōes brasileiras em função de suas competências tecnológicas, as quais são identificadas por classes tecnológicas, segundo a International Patent Classification - IPC, presentes nos depósitos de patentes (BADEPI/INPI) no período 2000-2011. A classificação é baseada em três indicadores: coeficiente de Zipf, índice de Gini e estatística I de Moran. Os resultados indicam que o grau de hierarquia e concentração em regiōes é menor em tecnologias de química de alimentos, engenharia mecânica e civil, sendo tais tecnologias mais presentes em regiões menos centrais. Por outro lado, as tecnologias de engenharia elétrica e telecomunicações, biológicas e nanotecnologias apresentam um grau de hierarquia e concentração maior, sendo dominadas por São Paulo, Campinas e Rio de Janeiro. Os padrōes de aglomeração indicam a existência de associação espacial positiva destas tecnologias no Sudeste e Sul do Brasil, em particular nas capitais dos estados e na região de Campinas.

PALAVRAS-CHAVE | Hierarquia Urbana; Concentração; Patentes; Regiōes Inventivas; Brasil

CÓdigos-JEL | O3; R1; D39

\footnotetext{
Os autores agradecem o suporte de agências de fomento, como CNPq e Fapemig, e à equipe de profissionais do INPI.

. Universidade Federal de Juiz de Fora (UFJF), Juiz de Fora (MG), Brasil. E-mail: rrodriguez431@gmail.com.

... Universidade Federal de Juiz de Fora (UFJF), Juiz de Fora (MG), Brasil. E-mail: eduardo.goncalves@uff.edu.br.
} 


\title{
Hierarchy and concentration in Brazilian regional distribution of inventions by types of technologies
}

\begin{abstract}
This article aims to propose a classification of Brazilian regions according to their technological skills. These are identified by technological classes, according to the International Patent Classification -IPC stemming from BADEPI/INPI for the period 2000-2011. The classification is based on three indicators: Zipf, Gini and Moran's I (global and local) coefficients. Results indicate that the degree of hierarchy and concentration in Brazilian regions are smaller in technologies of chemistry food, mechanical and civil engineering, as such technologies are also present in less central regions. In contrast, technologies of electrical engineering and telecommunications, biological and nanotechnologies present a greater degree of hierarchy and concentration, mainly located in São Paulo, Campinas and Rio de Janeiro. Clustering patterns indicate the existence of positive spatial association of these technologies in the Southeast and South regions of Brazil, particularly in the state capitals and Campinas region.
\end{abstract}

KeYwords | Urban Hierarchy; Concentration; Patents; Inventive Regions; Brazil

JEL CODES | O3; R1; D39 


\section{Introdução}

Existe um grande conjunto de evidências apontando que a atividade inventiva e a inovativa são espacialmente concentradas (FELDMAN, 1999; FELDMAN; FLORIDA, 1994; GLAESER et al., 1992). Segundo Carlino e Kerr (2014), a inovação é mais concentrada, em geral, do que a atividade produtiva. Grande parte dessa concentração está atrelada aos aspectos essencialmente urbanos do processo de invenção/inovação. Simmie (2003a), por exemplo, aponta que as vantagens de escala das grandes cidades, que concentram vantagens decorrentes de economias de urbanização e de localização, parecem ser a principal motivação para a aglomeração da atividade inovadora em centros urbanos. Os motivos para a desigualdade na distribuição espacial da inovação são vários, mas, por sua vez, estão relacionados à distribuição desigual de universidades e empresas dispostas a investir em pesquisa e desenvolvimento (P\&D) (JAFFE, 1989), de mão de obra qualificada (MARSHALL, 1983; KRUGMAN, 1991) e de transbordamentos de conhecimento, os quais apresentam caráter localizado (AUDRETSCH; FELDMAN, 1996).

No Brasil, as principais contribuições na literatura empírica sobre inovação regional apontam que:

- há um regime do tipo Norte-Sul no sistema de inovação brasileiro, com predominância do Sul-Sudeste nos indicadores de inovação ou atividade tecnológica (GONÇALVES, 2007; DINIZ; GONÇALVES, 2005; SUZIGAN et al., 2006);

- a escala urbana é condicionante importante da inovação regional (GONÇALVES; ALMEIDA, 2009; ARAUJO; GARCIA, 2014; GARCIA, 2016);

- existem de efeitos inerciais temporais e espaciais sobre a inovação (MONTENEGRO; GONÇALVES; ALMEIDA, 2011), perpetuando a importância relativa das regiōes mais inovadoras;

- há determinadas regiōes que apresentam esforços na tentativa de recuperar o atraso tecnológico (LEMOS et al., 2006);

- o potencial inovativo do Brasil, baseado em indicadores de habilidades dos trabalhadores, ocupaçóes de P\&D e intensidade tecnológica setorial, se concentra em 15 clusters de inovação que englobam 847 municípios, sendo 93\% destes localizados nas regiôes Sul e Sudeste (GÓIS SOBRINHO; AZZONI, 2016). 
O presente trabalho busca contribuir para a literatura ao investigar a distribuição de competências tecnológicas avaliadas segundo as classes tecnológicas existentes nos registros de depósitos de patentes. Este é um aspecto diferencial de outros estudos, que, em geral, usam números de patentes. Além disso, em função dos resultados de trabalhos empíricos prévios, sabe-se que a capacidade tecnológica regional favorece as regiōes do Sudeste e Sul do Brasil. No entanto, a distância relativa entre as áreas de elevada centralidade e outras menos centrais pode variar em função do tipo de tecnologia e do grau de intensidade tecnológica. Para avaliar estes aspectos não contemplados em trabalhos anteriores, medidas que revelam a hierarquia, a concentração e os padrões de dependência espacial das invenções urbanas são analisadas, respectivamente, por meio da Lei de Zipf, coeficiente de Gini e I de Moran local. Outra perspectiva que difere dos estudos anteriores é a unidade espacial de análise: regiões de influência do IBGE, que podem ser mais adequadas para lidar com o fenômeno da invenção/inovação, essencialmente urbano.

A seguir, é apresentada a literatura que discute o caráter urbano da atividade inventiva. Na sequência expõe-se a metodologia para mensuração de hierarquias urbanas, além das medidas de Gini e I de Moran, e aborda-se o procedimento de construção da base de dados utilizada, assim como o corte regional de análise. São discutidos os resultados dos indicadores baseados na Lei de Zipf, no índice de Gini e no I de Moran, e, por fim, são tecidas as conclusões do estudo.

\section{Revisão da literatura}

A literatura que se dedica à análise da distribuição espacial da atividade econômica é conhecida desde autores como Weber, Lösch, Von Thünen e Isard, mas é Marshall (1983) o primeiro a adquirir notoriedade na análise distributiva do espaço no estudo das economias de aglomeração, entendidas pelo conceito de externalidades (MCCANN, 2014; JOHANSSON, 2014). Marshall identifica três principais razões para a ocorrência da escala de aglomeração em uma localidade: os transbordamentos de conhecimento, insumos locais não comercializáveis e agrupamentos locais de trabalhadores qualificados. Ohlin (1933) distingue dois tipos de economias de aglomeração, a saber, as economias de localização e as economias de urbanização, sendo as economias de localização aquelas que ocorrem somente quando existem benefícios às empresas da expansão de sua própria indústria, resultando em aglomerações industriais, enquanto as economias de urbanização ocorrem quando a expansão da área urbana beneficia firmas próximas de uma variedade de indústrias, conduzindo ao crescimento da região. 
Para incorporar a discussão de hierarquias na distribuição da atividade inventiva, utiliza-se o conceito de hierarquia urbana, desenvolvido a partir da teoria dos lugares centrais de Christaller (1966), que enfatiza o papel de como as atividades são distribuídas entre as localidades centrais e como essas localidades centrais são distribuídas em um país ou região. O principal tema discutido por tal teoria é a presença de diferentes localizações que possuem diferentes níveis de centralidade, nos quais bens e serviços são providos em uma base hierárquica (MULLIGAN, 1984; HSU, 2012), contemplando diversos trabalhos empíricos no Brasil (SIMÕES et al., 2010; RUIZ, 2005) e internacionalmente (LE GALLO; CHASCO, 2008).

As contribuições apresentadas por tais autores são reinterpretadas durante a década de 1990, a partir dos trabalhos da nova geografia econômica (KRUGMAN, 1991; FUJITA, KRUGMAN; VENABLES, 2001). Nessa visão, os centros urbanos são entendidos como localidades onde a variedade e a escala ocorrem conjuntamente, sendo entendidas como forças "centrípetas" capazes de encorajar os fatores a se alocarem nas cidades (MCCANN, 2014).

No campo da economia da inovação, o interesse na análise regional surge a partir do desenvolvimento do conceito de transbordamentos de conhecimento localizado. Uma série de estudos empíricos reforça a ideia de que os transbordamentos são delimitados geograficamente, como Jaffe (1989), Jaffe et al. (1993), Audretsch e Feldman (1996) e Audretsch e Stephan (1996).

Neste contexto de inovação regional, existem majoritariamente duas áreas de análise espacial. A primeira possui um enfoque particular na dinâmica temporal da atividade inovadora em um país ou região. Ceh (2001) apresenta a geografia da inovação para as invençôes patenteadas dos Estados Unidos de 1978 até 1998, investigando os fatores socioeconômicos correlacionados à atividade inventiva. Moreno, Paci e Usai (2005) estabelecem uma análise do período de 1980 a 2000 para regiôes europeias, identificando de que forma a especialização da produção se relaciona com a especialização da inovação e com os transbordamentos ao longo do tempo.

A segunda área de análise possui um enfoque particular na compreensão da distribuição espacial da atividade inovadora, buscando entender porque determinados meios urbanos possuem maior capacidade inventiva do que os demais. Higgs (1971) analisa a relação entre população urbana e patentes per capita, em uma tentativa de capturar as relaçôes entre os meios urbanos e a capacidade inventiva. Carlino, Chaterjee e Hunt (2007) buscam identificar a relação entre inovação e atividade urbana por meio da relação entre patentes per capita e densidade de empregos. A relação entre densidade urbana e inovação, em particular, é ênfase de diversos au- 
tores, como Acs, Anselin e Varga (2002), Simmie (2003a, 2003b), Mukim (2012) e Glaeser et al. (1992).

Existem diversas metodologias de análise da distribuição espacial da atividade inovadora, sendo que uma síntese dessas medidas é apresentada por Nakamura e Paul (2010). Em geral, os economistas utilizam modelos econométricos espaciais para estabelecer relações entre fatores econômicos, sociais e geográficos. $\mathrm{Na}$ análise exploratória da distribuição espacial, diversas medidas são abordadas, como o coeficiente de Gini e o I de Moran. O'Huallachain (1999) aborda uma metodologia de mensuração de hierarquias inventivas por meio da estimação econométrica de um coeficiente hierárquico, seguindo uma regra de potência conhecida como Lei de Zipf.

Maliszewski e O'Huallachain (2012) discutem tal medida de hierarquia urbana que, combinada a medidas distributivas (Gini) e de dependência espacial (I de Moran), geram boas informações sobre a distribuição espacial, medida para grupos específicos de patentes, sendo um trabalho pioneiro na utilização de regras "classificação-tamanho" sobre leis de potência (no caso, a Lei de Zipf) para patentes com resultados comparáveis e interpretáveis. Seus resultados apontam que existem diferenças fundamentais entre as categorias de patentes estudadas, sendo algumas altamente hierarquizadas (concentradas em grandes metrópoles) e desigualmente distribuídas, como tecnologias de maior sofisticação (semicondutores, nuclear), enquanto outras são o oposto, como agricultura, pecuária e sistemas de energia, no caso norte-americano.

No Brasil, existem alguns estudos que aplicam a Lei de Zipf na distribuição populacional, como o de Simões et al. (2010), que avalia os municípios mineiros em cortes de anos. Ruiz (2005) apresenta um comparativo da estrutura urbana brasileira com a estrutura urbana americana, por municípios.

Albuquerque (2000) identifica algumas peculiaridades das patentes brasileiras para o período 1980-1995: alta participação de patentes individuais; empresas estrangeiras com atividades tecnológicas importantes; e baixo envolvimento de firmas nacionais em atividades de P\&D. Por outro lado, as características em comum com patentes de países desenvolvidos são: empresas domésticas como maiores patenteadoras; distribuição das patentes por firmas em forma de U; evidências de grandes firmas possuidoras de alta diversidade tecnológica; e uma participação relativamente pequena de empresas que possuem mais de uma patente durante o período de análise. 
Lemos et al. (2006) afirmam que o sistema brasileiro de inovação está cada vez menos centralizado em São Paulo, migrando para um conjunto de metrópoles emergentes em um grupo denominado "polígono de desenvolvimento", do qual fazem parte Belo Horizonte, Curitiba e Porto Alegre. Esse diagnóstico se inicia pelas evidências apontadas na atividade industrial, que nos últimos anos vem se afastando de São Paulo e migrando para outras metrópoles, tendo por base as conjunturas dos anos 1980 e 1990 que apontam queda na taxa de excedente industrial em São Paulo. Mesmo assim, as regiôes de São Paulo e Campinas respondem pela maior parte das invenções do país. Em geral, o padrão de distribuição regional das atividades de ciência, tecnologia e inovação ocorre ao longo do eixo das principais rodovias do estado e no entorno de áreas metropolitanas como São Paulo e Campinas, além de outras regiōes que possuem forte presença de instituições de ensino e pesquisa (SUZIGAN et al., 2006; MASCARINI, 2012; MONTENEGRO; GONÇALVES; ALMEIDA, 2011).

Gonçalves (2007) apresenta uma análise exploratória de dados espaciais sobre os depósitos brasileiros de patentes per capita para o período 1999-2001, com o intuito de conhecer a distribuição geográfica da inovação, ao nível de microrregiōes geográficas brasileiras. Seus resultados apontam a existência de autocorrelação espacial e um regime de polarização do tipo Norte-Sul. Recentemente, Araújo e Garcia (2014), ao nível de microrregiōes, e Góis Sobrinho e Azzoni (2016), no âmbito de municípios, destacam a concentração da inovação no Sul e Sudeste e indicam a existência de transbordamentos por externalidades advindas da diversificação da atividade econômica.

O presente artigo descreve a hierarquia urbana de competências tecnológicas regionais, a partir da frequência de códigos de patentes, com indicadores e metodologia não usados anteriormente. Um dos resultados da literatura aqui discutida é a indicação de concentração espacial da atividade tecnológica nas regiões mais desenvolvidas do Brasil (Sudeste e Sul), em geral, usando o número de invenções medidas por patentes. Entretanto, esta concentração pode ser maior ou menor de acordo com o tipo de tecnologia e seu grau de intensidade tecnológica. Ao revelar essa distribuição de competências regionais, o artigo fornece informações sobre o papel e a especialização tecnológica tanto de centros urbanos de posição elevada na centralidade urbana, quanto daqueles que possuem posição de menor destaque no sistema regional de inovações do Brasil. Ao combinar três medidas (coeficiente de Zipf, coeficiente de Gini e I de Moran), o estudo apresenta os graus de desigualdade, de hierarquia e de agrupamento espacial de diferentes subcategorias tecnológicas no sistema de inovação brasileiro, analisado por regiôes de influência. 


\section{Metodologia}

Segundo Newman (2005), hierarquia é um conjunto de unidades classificadas por algum critério. Neste caso, pretende-se construir uma hierarquia urbana de invenção, ou seja, um conjunto de unidades regionais classificadas por suas potencialidades inventivas em diferentes tecnologias, a partir da frequência de códigos de patentes presentes no total dos registros de depósitos brasileiros, que possuíam endereços válidos dos inventores, no período 2000-2011.

A medida de hierarquia a ser utilizada é uma lei de potência conhecida como Lei de Zipf. Muitos processos seguem uma relação envolvendo leis de potência, principalmente na física (como terremotos), na biologia (espécies em extinção) e também nas ciências sociais (tamanho de cidades e renda). Por intermédio dessa lei, estima-se a inclinação de uma distribuição do tipo classificação-tamanho (rank-size), como coeficientes de leis de potência (GUERRIERO, 2012; NEWMAN, 2005). Para existir uma lei de potência, a relação deve ser definida como:

$$
y=a x^{k}
$$

Em que $a$ é uma constante de proporcionalidade e o expoente $k$ é uma constante, $y$ é a variável de interesse e $x$ é a variável de classificação.

Para expressar esses resultados em um gráfico log-log, é possível reescrever a equação anterior como:

$$
\log (y)=k \log (x)+\log (a)
$$

A equação (2) se apresenta com a mesma forma da equação de uma reta com coeficiente angular $k$, sendo $y$ a variável de interesse e $x$ a variável de classificação.

A estimação de uma regressão linear simples, com ajuste perfeito de $100 \%$, deve encontrar um coeficiente $k$ equivalente a -1 . O coeficiente deve ser negativo, pois, naturalmente, a relação é inversa. Coeficientes altos em módulo indicam uma alta hierarquização, enquanto coeficientes mais próximos de zero indicam que não há uma hierarquia, como, por exemplo, nos casos em que a distribuição do evento pode ser ubíqua, aleatória. A estatística $\mathrm{R}^{2}$ é uma referência que permite indicar o quão eficiente é o ajuste linear, uma vez que para muitas relações os ajustes quadráticos parecem ser mais adequados à distribuição dos dados. Entretanto, não estariam de acordo com a regra de Zipf. Para o problema em questão, a Lei de Zipf será definida como: 


$$
\text { "Freq IPCs" }{ }_{i z}=c_{z} / \operatorname{rank}_{i z}^{\alpha}
$$

Em que para cada tecnologia z, "Freq IPCs" ${ }_{i t}$ é a quantidade de frequências de cada unidade regional $i$, rank $_{i z}$ é a classificação das unidades regionais $i$ de acordo com o somatório de todos os valores de "Freq IPC $\S^{\prime \prime}{ }_{i}$ ou seja, o ranking regional de acordo com os totais de frequências. $c_{z}$ é uma constante e $\alpha$ é o expoente de concentração. Fazendo a transformação linear, tem-se que:

$$
\ln " \text { Freq IPCs" }{ }_{i z}=\ln z-\alpha \ln \operatorname{rank}_{i z}
$$

Essa transformação linear será estimada por Mínimos Quadrados Ordinários (MQO) para cada uma das $z$ tecnologias, e o $\alpha$ estimado será o coeficiente de Zipf. Quanto mais negativa essa relação, ou seja, quanto mais o coeficiente se afasta de -1 em direção a números mais negativos, mais desproporcional a relação se apresenta. Por exemplo, se o coeficiente é perfeitamente igual a -2 , em vez do $\mathrm{N}=2$ ter como equivalente a metade de ocorrências do primeiro lugar, terá um quarto. Isto é, o "degrau" entre as regiōes aumenta. Quanto mais positiva (próxima de zero) esta relação é, menos hierarquia existe, ou seja, não há uma distância de ocorrências entre as regiōes. Se o coeficiente for exatamente igual a 1 e o ajuste for perfeito, tem-se uma hierarquia distributiva de Zipf, que significa que todas as regiōes apresentam um número de frequências proporcional ao longo da hierarquia, sendo desigualmente distribuído, mas hierarquizado de acordo com o critério estabelecido de classificação.

Newman (2005), Holmes e Lee (2010) e Maliszewski e O’Huallachain (2012) sugerem a utilização da estimação de Zipf somente para a cauda superior, que será delimitada como as 20 primeiras regiōes da distribuição para cada subdomínio tecnológico. Esse corte é baseado em dois critérios: número de regiôes com ocorrências do menor subdomínio tecnológico (22); e priorização das regiões com alto e médio índice de ocorrências, descartando da análise as regiôes nulas e de ocorrências baixas que poderiam enviesar como outliers inferiores a estimação. Em média, as 20 primeiras regiōes de cada domínio tecnológico correspondem à maioria dos dados de frequência, ou seja, $81,35 \%$ do total de IPCs da base de dados. Em alguns casos, a concentração atinge o valor de $83,69 \%$ no domínio da engenharia elétrica ou, no mínimo, 79,4\%, no caso do domínio de química.

A literatura sugere que o procedimento para a análise da Lei de Zipf envolve limitar a "cauda superior" para garantir a linearidade. É importante ressaltar também que a linearidade da distribuição total não garante a linearidade das distribuiçôes 
dos subdomínios tecnológicos, mas é uma referência de partida. Portanto, para preservar a linearidade, a distribuição sobre a qual será calculada a Lei de Zipf terá 20 regióes para cada hierarquia a ser calculada. Com esse ajuste ao número de regiōes sob as quais será calculada a Lei de Zipf, os resultados, além de comparáveis entre os subdomínios, ficam menos sensíveis ao grande número de regiões com ocorrências nulas e reduzidas.

Tal procedimento resulta na melhora do ajuste dos coeficientes e na formação de um padrão aceitável de comparabilidade entre o coeficiente de Zipf dos subdomínios tecnológicos. A não linearidade da distribuição inteira é uma situação esperada, uma vez que temos poucas cidades grandes concentrando um elevado número de frequências de códigos IPCs e muitas cidades pequenas apresentando poucas ou praticamente nenhuma ocorrência de patente, e o procedimento adotado é adequado se a discussão dos resultados for ponderada somente aos 20 principais centros urbanos de cada subdomínio tecnológico.

Além da hierarquia, foi medida a concentração de patentes entre as regiōes, com base no coeficiente de Gini ${ }^{1}$ calculado de acordo com a seguinte expressão:

$$
G=\left(\frac{N}{N-1}\right)\left(\frac{1}{2} \sum_{i=1}^{N}\left|P_{i}-x_{i}\right|\right)
$$

Em que $N$ é o número de regiōes, $P_{i t}$ é a participação percentual da região $i$ no total de frequências e $x_{i}=1 / N$ sendo o valor esperado de porcentagem de frequências para cada regiāo se a distribuiçãa fosse completamente homogênea. Essa medida é calculada para as 161 regióes utilizadas na base de dados.

O I de Moran é uma medida que fornece um coeficiente de autocorrelação espacial, usando a medida de autocovariância na forma de produto cruzado. Algebricamente, a medida é definida por Anselin (1988) como:

$$
I=\frac{n}{S_{0}} \frac{\sum_{i} \sum_{j} w_{i j} z_{i} z_{j}}{\sum_{i=1}^{n} z_{i}^{2}}
$$

Em que $n$ é o número de regióes, $z$ denota os valores da variável de interesse padronizada, neste caso, a frequência de códigos IPCs em um subdomínio tecnológico específico, e $w_{i j}$ representa os valores médios da variável de interesse padronizada nas regiões vizinhas $i$ e $j$, definidos segundo uma matriz de ponderação espacial

1 A utilização do coeficiente de Gini deve-se à sua capacidade analítica da concentração das distribuiçốes, generalidade e principalmente comparabilidade dos resultados entre os subdomínios. O I de Moran (global e locais) é preferido devido à possibilidade de análise em mapas dos padrōes de associação espacial, o que facilita a interpretação dos resultados. 
W. $S_{0}$ equivale à operação $\sum_{i} \sum_{j} w_{i j}$, significando que todos os elementos da matriz de pesos espaciais $W$ devem ser somados. A partir dessa definição, o I de Moran é decomposto por meio do agrupamento da contribuição local de cada observação em quatro categorias (alto-alto, baixo-baixo, alto-baixo e baixo-alto), sendo conhecido como I de Moran local (ANSELIN, 1995) e definido como:

$$
I_{i}=z_{i} \sum_{j=1}^{J} w_{i j} z_{j}
$$

Em que o cálculo do coeficiente de I só abrange os vizinhos de cada unidade espacial $i$, de acordo com a matriz de pesos espaciais definida. Tanto o I de Moran global quanto os locais são calculados para as 161 regiōes da base de dados.

Os coeficientes de Zipf, Gini e os I de Moran global e locais, ao serem analisados de forma conjugada, fornecem padrões de cada subdomínio tecnológico a ser avaliado, auxiliando em duas dimensões: a hierárquica-distributiva e a espacial-aglomerativa. O coeficiente de Zipf indica a hierarquização por parte dos grandes centros tecnológicos com relaçáo aos menores, enquanto o Gini apresenta o quão concentrado é, de forma sintética, a distribuição. Uma vez identificados os padrões de hierarquia e concentração, os mapeamentos dos padrões de aglomeração ou desaglomeração são discutidos por meio do I de Moran.

\section{Base de dados}

Os dados são oriundos da Base de Dados Estatísticos de Propriedade Intelectual, versão 1.0, gerada pelo Instituto Nacional de Propriedade Intelectual (BADEPI/ INPI), cobrindo o período 2000-2011. Nessa base estão presentes as informaçôes referentes à localização da patente por região de residência dos seus inventores e a classificação do registro de patente em termos de subclasses tecnológicas, que segue a International Patent Classification (IPC), de 2008 ao nível de quatro dígitos, segundo a WIPO (2015). A IPC provê um sistema hierárquico de símbolos para classificação das patentes, de acordo com diferentes áreas tecnológicas às quais uma patente pode pertencer.

A base usada nesse trabalho, que combina informações úteis de localização do inventor e código IPC, possui 87.755 depósitos de patentes de municípios brasileiros para o período de 2000 a 2011. Como cada patente possui ao menos um código, há um múltiplo de códigos para cada região considerada no estudo, associada à localidade do inventor depositante. Ao se considerarem todos os códigos presentes 
num registro de patente, pretende-se captar todas as competências tecnológicas em cada região. Nesse sentido, a frequência dos códigos de patentes é a informação usada nos diversos indicadores que serão descritos a seguir.

Como uma patente pode ter inventores de diferentes regióes, os códigos de uma patente são atribuídos a todas as regiões a que pertencem seus inventores. Nesse sentido, se uma patente tem dois inventores de cidades diferentes, seus códigos são igualmente atribuídos às duas cidades, pois se considera que ambas as cidades possuem competências tecnológicas expressas pelos respectivos códigos.

A partir desse critério, foram contabilizadas 127.252 frequências de IPCs ao nível de quatro dígitos nos registros de patentes de todos os anos do período 2000-2011. A opção por utilizar o estoque de registros de IPCs de um período longo se justifica pela necessidade de minimizar distorçôes oriundas da escolha de anos específicos e de produzir um retrato das especialidades tecnológicas de cada região num período representativo, que envolve toda a década de 2000. Outro procedimento adotado foi o agrupamento dos IPCs por domínios e subdomínios tecnológicos (Quadro 1), seguindo a metodologia de Schmoch (2008), desenvolvida para o World International Patent Office (WIPO).

\section{QUADRO 1}

Agrupamento das subclasses tecnológicas em domínios e subdomínios tecnológicos

\begin{tabular}{|c|l|l|}
\hline Cód. & \multicolumn{1}{|c|}{ Tecnologia } & \multicolumn{1}{c|}{ Subdomínio tecnológico } \\
\hline 1 & Engenharia elétrica & $\begin{array}{l}\text { Maquinaria elétrica e aparatos, energia elétrica (1); tecnologia } \\
\text { audiovisual e telecomunicaçôes (2 e 3); comunicação } \\
\text { digital (4); processo de comunicação básica (5); tecnologia } \\
\text { de computadores (6); métodos de TI para gestão (7); } \\
\text { semicondutores (8); }\end{array}$ \\
\hline 2 & Instrumentos & $\begin{array}{l}\text { Ótica (9); medição e análise de materiais biológicos (10 e 11); } \\
\text { controle (12); tecnologia médica (13); }\end{array}$ \\
\hline 3 & Química & $\begin{array}{l}\text { Produtos orgânicos elaborados (14); biotecnologia (15); } \\
\text { produtos farmacêuticos (16); química macromolecular, } \\
\text { polímeros (17); química de alimentos (18); química de } \\
\text { materiais (19); materiais, metalurgia (20); tecnologia de } \\
\text { superfície, revestimentos (21); tecnologia das microestruturas } \\
\text { e nanotecnologia (22); engenharia química e tecnologia } \\
\text { ambiental (23 e 24); }\end{array}$ \\
\hline 4 & Engenharia mecânica & $\begin{array}{l}\text { Manipulação (25); máquinas, ferramentas (26); maquinaria } \\
\text { têxtil e de papel (28); outras maquinarias especiais (29); } \\
\text { processos térmicos e aparatos (30); componentes mecânicos } \\
\text { (31); transporte (32) }\end{array}$ \\
\hline 5 & Outros & $\begin{array}{l}\text { Mobília, jogos (33); outros produtos de consumo (34); } \\
\text { engenharia civil (35) }\end{array}$ \\
\hline
\end{tabular}

Fonte: Adaptado de Schmoch (2008). 
Hierarquia e concentração na distribuição regional brasileira de invenções...

TABELA 1

Estatísticas descritivas e informações básicas das frequências de códigos IPCs citados de acordo com as principais regiōes intermediárias de articulação urbana - 2000-2011

\begin{tabular}{|c|c|c|c|c|}
\hline Ranking & Nome da região intermediária & $\begin{array}{l}\text { Número de } \\
\text { municípios }\end{array}$ & $\begin{array}{l}\text { Município } \\
\text { polo }(\%)\end{array}$ & $\begin{array}{l}\text { Total de } \\
\text { frequências }\end{array}$ \\
\hline 1 & São Paulo (SP) & 55 & 70,68 & 35.671 \\
\hline 2 & Campinas (SP) & 67 & 43,29 & 10.272 \\
\hline 3 & Rio de Janeiro (RJ) & 34 & 75,80 & 9.176 \\
\hline 4 & Belo Horizonte (MG) & 75 & 72,96 & 7.160 \\
\hline 5 & Curitiba (PR) & 25 & 82,15 & 6.973 \\
\hline 6 & Porto Alegre (RS) & 48 & 70,98 & 5.152 \\
\hline 7 & Caxias do Sul (RS) & 23 & 60,58 & 2.892 \\
\hline 8 & Ribeirão Preto (SP) & 43 & 47,19 & 2.723 \\
\hline 9 & Joinville (SC) & 22 & 74,82 & 2.689 \\
\hline 10 & Florianópolis (SC) & 23 & 62,50 & 2.685 \\
\hline 11 & São José dos Campos (SP) & 32 & 55,81 & 2.229 \\
\hline 12 & Brasília (DF) & 13 & 95,47 & 1.966 \\
\hline 13 & Blumenau (SC) & 32 & 50,67 & 1.715 \\
\hline 14 & São José do Rio Preto (SP) & 63 & 38,43 & 1.551 \\
\hline 15 & Goiânia (GO) & 34 & 79,75 & 1.526 \\
\hline 16 & Londrina (PR) & 38 & 59,09 & 1.457 \\
\hline 17 & Sorocaba (SP) & 29 & 43,77 & 1.437 \\
\hline 18 & Vitória (ES) & 21 & 44,10 & 1.433 \\
\hline 19 & São Carlos (SP) & 7 & 96,32 & 1.384 \\
\hline 20 & $\begin{array}{l}\text { Novo Hamburgo - São Leopoldo } \\
\text { (RS) }\end{array}$ & 17 & 68,57 & 1.365 \\
\hline Total & & 701 & 79,72 & 101.456 \\
\hline \multicolumn{2}{|c|}{ UnidadelOcorrências } & Desvio Padrão & Mediana & Máximo \\
\hline \multicolumn{2}{|c|}{ Municípios } & 686,91 & 5 & 25.213 \\
\hline \multicolumn{2}{|c|}{ Regiōes Intermediárias } & 3260,57 & 105 & 35.671 \\
\hline
\end{tabular}

Fonte: Base de Dados Estatísticos de Propriedade Intelectual, Instituto Nacional de Propriedade Intelectual - BADEPI/INPI (versão 1.0). Elaboração dos autores.

A unidade espacial de análise utiliza o conceito de regiōes intermediárias de articulação urbana, que considera a divisão urbano-regional a partir das Regiōes de Influência das Cidades (Regic). As regiōes intermediárias de articulação urbana, 
formadas de acordo com o traço característico de polarização dos municípios por um centro de atendimento de bens e serviços, são compostas por 161 regiōes e possuem uma diferenciação aglomerativa quando se foca na capacidade de invenção, medida por frequência de IPCs citados.

Sabe-se que a invenção é um fenômeno essencialmente urbano e que o espaço urbano pode ter grau de influência variável sobre outros espaços urbanos, dependendo do nível de centralidade dos serviços ali reunidos (CHRISTALLER, 1966). A Regic é construída sobre esta lógica. As vantagens do uso da Regic dizem respeito ao fato de que esta regionalização foi construída de forma a refletir o "espaço de fluxos" existente no interior de regiōes polarizadas e polarizadoras.

\section{FIGURA 1}

Distribuição espacial das frequências de subclasses tecnológicas dos depósitos de patentes brasileiros, segundo o conceito de regiōes intermediárias da divisão urbano-regional da Regic - 2000-2011

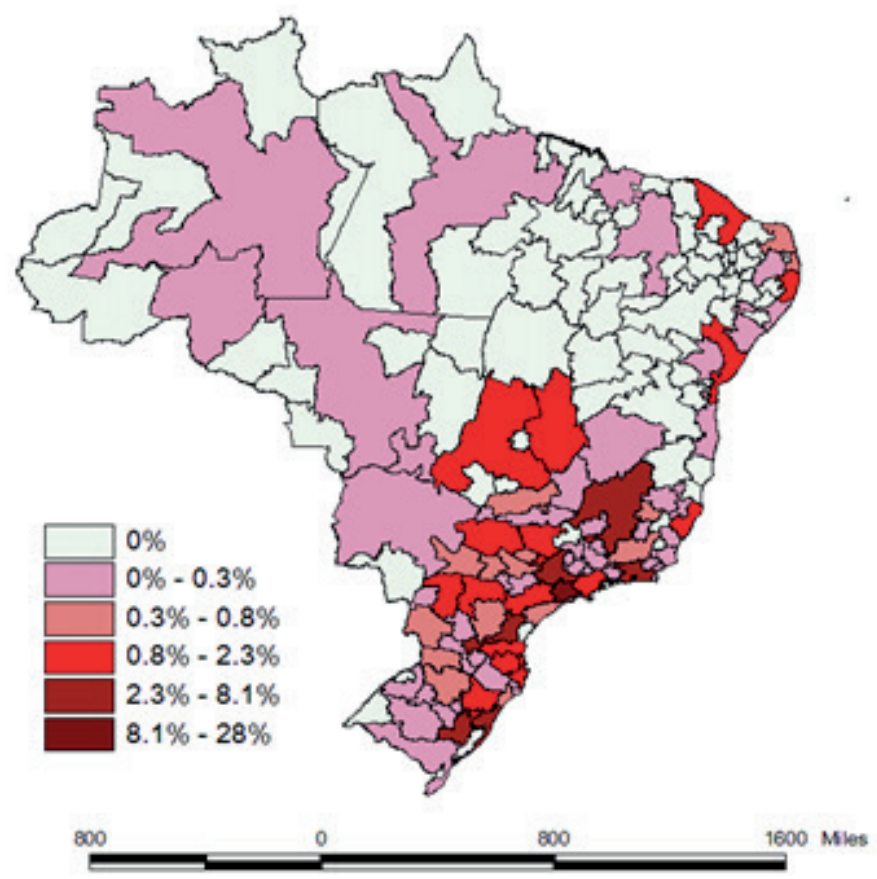

Fonte: Base de Dados Estatísticos de Propriedade Intelectual, Instituto Nacional de Propriedade Intelectual - BADEPI/INPI (versão 1.0). Elaboração dos autores.

A região intermediária de Campinas, por exemplo, possui 10.272 frequências de classificação de patentes, sendo que desse total somente 4.447 (43\%) são efetivamente da cidade de Campinas (Tabela 1). Parte destas frequências é atribuída a 
um grupo de municípios como Piracicaba, Vinhedo, Limeira, Valinhos e Americana (27\%). Em contraste, a região intermediária do Rio de Janeiro, que possui 9.177 frequências de códigos IPCs, registra somente na cidade do Rio de Janeiro 6.955 ocorrências, representando $75 \%$ da região, sendo outra parcela significativa assumida pelos municípios de Niterói e Petrópolis.

A distribuição espacial do estoque de frequências de códigos IPCs dos registros de depósitos de patentes do período 2000-2011 pode ser observada na Figura 1. Informações adicionais sobre a dinâmica temporal do estoque de frequências podem ser vistas no Apêndice A.

\section{Resultados}

\subsection{Hierarquia e concentração de invenções}

A Tabela 2 apresenta os resultados das estimativas dos coeficientes de Zipf, de Gini e de I de Moran para cada um dos 35 subdomínios tecnológicos. ${ }^{2}$ A primeira e a segunda colunas trazem o código e descrição de cada subdomínio de acordo com a definição de Schmoch (2008). A terceira coluna apresenta o total de regiôes que possuem ao menos uma ocorrência de classificação tecnológica. Nas últimas colunas encontram-se algumas estatísticas comparadas aos resultados de uma distribuição geral das atividades, com o intuito de destacar particularidades regionais em algumas tecnologias.

Em geral, todos os subdomínios tecnológicos brasileiros são hierarquizados ainda que alguns mais, outros menos - e alguns apresentam um ajuste quase perfeito da Lei de Zipf, como os subdomínios tecnológicos 18 (química de alimentos) e 35 (engenharia civil), com coeficientes de Zipf muito próximos a -1 e ajuste do $\mathrm{R}^{2} \mathrm{de}$ 0,990 e 0,982 , respectivamente. O caso do subdomínio química de alimentos ilustra bem a regularidade empírica prevista pela Lei de Zipf: São Paulo, que é a região com mais frequências nesse subdomínio, possui $21,85 \%$ do total de frequências. O segundo colocado no ranking, Campinas, caso fosse uma Lei de Zipf perfeita, deveria ser a metade do primeiro no ranking, ou seja, 10,92\%. O valor encontrado foi de $11,03 \%$, mostrando que o ajuste é muito próximo do valor de Zipf. Essa lógica se segue para um terço na terceira região, um quarto na quarta região, até vinte avos, que é a vigésima região na classificação.

2 Embora a Lei de Zipf seja investigada para a cauda superior do total de regiôes (20 principais), os cálculos do coeficiente de Gini e I de Moran são realizados considerando-se o total das 161 regiōes da Regic. 
TABELA 2

Resultados das estimaçôes dos coeficientes de Zipf, Gini e I de Moran para estatísticas de patentes e códigos IPCs

Brasil - 2000-2011

\begin{tabular}{|c|c|c|c|c|c|c|c|c|c|}
\hline \multirow[b]{2}{*}{ Cód. } & \multirow[b]{2}{*}{$\begin{array}{l}\text { Subdomínio } \\
\text { tecnológico }\end{array}$} & \multirow[b]{2}{*}{$\begin{array}{l}\mathrm{N}^{\circ} \\
\text { Reg. }\end{array}$} & \multicolumn{3}{|c|}{ Coeficientes } & \multirow{2}{*}{$\begin{array}{c}\% \text { das } \\
\text { ocorrências } \\
\text { nas top } 10 \\
\text { regiôes }\end{array}$} & \multicolumn{3}{|c|}{ Top 5 regióes em cada tecnologia } \\
\hline & & & $\operatorname{Zipf}\left(\mathbf{R}^{2}\right)$ & Gini & $\begin{array}{c}\text { I de } \\
\text { Moran } \\
\text { (P-Valor) }\end{array}$ & & $\begin{array}{c}\text { Class. no } \\
\text { ranking } \\
\text { geral }\end{array}$ & Regiáo & $\begin{array}{c}\text { \% do } \\
\text { total } \\
\text { de } \\
\text { ocorrências }\end{array}$ \\
\hline \multirow{5}{*}{1} & \multirow{5}{*}{$\begin{array}{l}\text { Maquinaria } \\
\text { elétrica e } \\
\text { aparatos, energia } \\
\text { elétrica }\end{array}$} & & \multirow{5}{*}{$\begin{array}{c}-1,104^{* * *} \\
(0,970)\end{array}$} & \multirow{5}{*}{0,712} & \multirow{5}{*}{$\begin{array}{l}0,1527 \\
(0,001)\end{array}$} & \multirow{5}{*}{70,17} & 1 & São Paulo (SP) & 31,87 \\
\hline & & & & & & & 2 & Campinas (SP) & 7,95 \\
\hline & & 99 & & & & & 4 & Belo Horizonte (MG) & 6,09 \\
\hline & & & & & & & 5 & Curitiba (PR) & 4,99 \\
\hline & & & & & & & 3 & Rio de Janeiro (RJ) & 4,64 \\
\hline \multirow{5}{*}{$2 \mathrm{e} 3$} & \multirow{5}{*}{$\begin{array}{l}\text { Tecnologia } \\
\text { audiovisual e } \\
\text { telecomu- } \\
\text { nicaçōes }\end{array}$} & & \multirow{5}{*}{$\begin{array}{c}-1,218^{* * *} \\
(0,967)\end{array}$} & \multirow{5}{*}{0,720} & \multirow{5}{*}{$\begin{array}{l}0,1091 \\
(0,024)\end{array}$} & \multirow{5}{*}{71,17} & 1 & São Paulo (SP) & 35,02 \\
\hline & & & & & & & 2 & Campinas (SP) & 7,44 \\
\hline & & 95 & & & & & 3 & Rio de Janeiro (RJ) & 7,39 \\
\hline & & & & & & & 4 & Belo Horizonte (MG) & 6,50 \\
\hline & & & & & & & 5 & Curitiba (PR) & 6,15 \\
\hline \multirow{5}{*}{4} & \multirow{5}{*}{$\begin{array}{l}\text { Comunicação } \\
\text { digital }\end{array}$} & & \multirow{5}{*}{$\begin{array}{c}-1,122^{* * *} \\
(0,981)\end{array}$} & \multirow{5}{*}{0,751} & \multirow{5}{*}{$\begin{array}{l}0,2111 \\
(0,000)\end{array}$} & \multirow{5}{*}{68,32} & 1 & São Paulo (SP) & 27,33 \\
\hline & & & & & & & 2 & Campinas (SP) & 14,06 \\
\hline & & 53 & & & & & 3 & Rio de Janeiro (RJ) & 6,34 \\
\hline & & & & & & & 4 & Belo Horizonte (MG) & 5,74 \\
\hline & & & & & & & 12 & Brasília (DF) & 4,36 \\
\hline \multirow{5}{*}{5} & \multirow{5}{*}{$\begin{array}{l}\text { Processo de } \\
\text { comunicaçăo } \\
\text { básica }\end{array}$} & & \multirow{5}{*}{$\begin{array}{c}-0,926^{* * *} \\
(0,973)\end{array}$} & \multirow{5}{*}{0,741} & & & 1 & São Paulo (SP) & 24,26 \\
\hline & & & & & & & 2 & Campinas (SP) & 10,65 \\
\hline & & 41 & & & $\begin{array}{l}0,1737 \\
(0,000)\end{array}$ & 62,13 & 3 & Rio de Janeiro (RJ) & 7,69 \\
\hline & & & & & & & 5 & Curitiba (PR) & 6,51 \\
\hline & & & & & & & 4 & Belo Horizonte (MG) & 3,55 \\
\hline & & & & & & & 1 & São Paulo (SP) & 28,43 \\
\hline & & & & & & & 2 & Campinas (SP) & 12,53 \\
\hline 6 & $\begin{array}{l}\text { Tecnologia de } \\
\text { computadores }\end{array}$ & 76 & $\begin{array}{c}-1,169^{* * *} \\
(0,988)\end{array}$ & 0,735 & $\begin{array}{l}0,1880 \\
(0,000)\end{array}$ & 70,19 & 5 & Curitiba (PR) & 6,58 \\
\hline & & & & & & & 3 & Rio de Janeiro (RJ) & 6,06 \\
\hline & & & & & & & 4 & Belo Horizonte (MG) & 5,21 \\
\hline & & & & & & & 1 & São Paulo (SP) & 36,61 \\
\hline & & & & & & & 4 & Belo Horizonte (MG) & 7,74 \\
\hline 7 & $\begin{array}{l}\text { Métodos de TI } \\
\text { para gestāo }\end{array}$ & 49 & $\begin{array}{c}-1,110^{* * *} \\
(0,963)\end{array}$ & 0,746 & $\begin{array}{l}0,1027 \\
(0,033)\end{array}$ & 70,32 & 2 & Campinas (SP) & 7,58 \\
\hline & & & & & & & 3 & Rio de Janeiro (RJ) & 5,81 \\
\hline & & & & & & & 5 & Curitiba (PR) & 5,48 \\
\hline
\end{tabular}


Hierarquia e concentração na distribuição regional brasileira de invenções...

TABELA 2

Resultados das estimações dos coeficientes de Zipf, Gini e I de Moran para estatísticas de patentes e códigos IPCs

Brasil - 2000-2011

\begin{tabular}{|c|c|c|c|c|c|c|c|c|c|}
\hline \multirow[b]{2}{*}{ Cód. } & \multirow[b]{2}{*}{$\begin{array}{l}\text { Subdomínio } \\
\text { tecnológico }\end{array}$} & \multirow[b]{2}{*}{$\begin{array}{c}\mathrm{N}^{\circ} \\
\text { Reg. }\end{array}$} & \multicolumn{3}{|c|}{ Coeficientes } & \multirow{2}{*}{$\begin{array}{c}\% \text { das } \\
\text { ocorrências } \\
\text { nas top } 10 \\
\text { regiōes }\end{array}$} & \multicolumn{3}{|c|}{ Top 5 regióes em cada tecnologia } \\
\hline & & & $\operatorname{Zipf}\left(\mathbf{R}^{2}\right)$ & Gini & $\begin{array}{c}\text { I de } \\
\text { Moran } \\
\text { (P-Valor) }\end{array}$ & & $\begin{array}{c}\text { Class. no } \\
\text { ranking } \\
\text { geral }\end{array}$ & Regiáo & $\begin{array}{c}\% \text { do } \\
\text { total } \\
\text { de } \\
\text { ocorrências }\end{array}$ \\
\hline \multirow{5}{*}{8} & \multirow{5}{*}{ Semicondutores } & & \multirow{5}{*}{$\begin{array}{c}-1,102^{* * *} \\
(0,967)\end{array}$} & \multirow{5}{*}{0,784} & \multirow{5}{*}{$\begin{array}{l}0,1710 \\
(0,000)\end{array}$} & \multirow{5}{*}{72,53} & 1 & São Paulo (SP) & 28,57 \\
\hline & & & & & & & 5 & Curitiba (PR) & 9,89 \\
\hline & & 35 & & & & & 2 & Campinas (SP) & 9,34 \\
\hline & & & & & & & 6 & Porto Alegre (RS) & 7,14 \\
\hline & & & & & & & 3 & Rio de Janeiro (RJ) & 6,04 \\
\hline \multirow{5}{*}{9} & \multirow{5}{*}{ Ótica } & & \multirow{5}{*}{$\begin{array}{c}-1,187^{* * *} \\
(0,996)\end{array}$} & \multirow{5}{*}{0,758} & \multirow{5}{*}{$\begin{array}{l}0,1904 \\
(0,000)\end{array}$} & \multirow{5}{*}{71,23} & 1 & São Paulo (SP) & 30,42 \\
\hline & & & & & & & 2 & Campinas (SP) & 12,50 \\
\hline & & 52 & & & & & 3 & Rio de Janeiro (RJ) & 9,49 \\
\hline & & & & & & & 5 & Curitiba (PR) & 5,57 \\
\hline & & & & & & & 4 & Belo Horizonte (MG) & 4,07 \\
\hline \multirow{5}{*}{$\begin{array}{c}10 \mathrm{e} \\
11\end{array}$} & \multirow{5}{*}{$\begin{array}{l}\text { Medição e } \\
\text { análise de } \\
\text { materiais } \\
\text { biológicos }\end{array}$} & & \multirow{5}{*}{$\begin{array}{c}-1,129^{* * *} \\
(0,968)\end{array}$} & \multirow{5}{*}{0,693} & \multirow{5}{*}{$\begin{array}{l}0,1731 \\
(0,000)\end{array}$} & \multirow{5}{*}{67,05} & 1 & São Paulo (SP) & 21,34 \\
\hline & & & & & & & 2 & Campinas (SP) & 10,88 \\
\hline & & 96 & & & & & 3 & Rio de Janeiro (RJ) & 10,61 \\
\hline & & & & & & & 4 & Belo Horizonte (MG) & 7,49 \\
\hline & & & & & & & 5 & Curitiba (PR) & 5,86 \\
\hline \multirow{5}{*}{12} & \multirow{5}{*}{ Controle } & & \multirow{5}{*}{$\begin{array}{c}-1,084^{* * *} \\
(0,972)\end{array}$} & \multirow{5}{*}{0,719} & & & 1 & São Paulo (SP) & 30,28 \\
\hline & & & & & & & 4 & Belo Horizonte (MG) & 7,66 \\
\hline & & 92 & & & $\begin{array}{l}0,1085 \\
(0,025)\end{array}$ & 66,95 & 5 & Curitiba (PR) & 7,13 \\
\hline & & & & & & & 6 & Porto Alegre (RS) & 5,76 \\
\hline & & & & & & & 3 & Rio de Janeiro (RJ) & 5,20 \\
\hline & & & & & & & 1 & São Paulo (SP) & 29,94 \\
\hline & & & & & & & 2 & Campinas (SP) & 7,60 \\
\hline 13 & $\begin{array}{l}\text { Tecnologia } \\
\text { médica }\end{array}$ & 100 & $\begin{array}{c}-1,103^{* * *} \\
(0,971)\end{array}$ & 0,714 & $\begin{array}{l}0,1452 \\
(0,003)\end{array}$ & 67,56 & 4 & Belo Horizonte (MG) & 6,57 \\
\hline & & & & & & & 3 & Rio de Janeiro (RJ) & 6,23 \\
\hline & & & & & & & 6 & Porto Alegre (RS) & 5,35 \\
\hline & & & & & & & 1 & São Paulo (SP) & 19,18 \\
\hline & & & & & & & 3 & Rio de Janeiro (RJ) & 16,64 \\
\hline 14 & Produtos & 80 & $\begin{array}{c}-1,234^{* * *} \\
(0,957)\end{array}$ & 0,763 & $\begin{array}{l}0,1775 \\
(0,000)\end{array}$ & 72,77 & 2 & Campinas (SP) & 16,35 \\
\hline & & & & & & & 4 & Belo Horizonte (MG) & 6,26 \\
\hline & & & & & & & 5 & Curitiba (PR) & 5,38 \\
\hline
\end{tabular}


TABELA 2

Resultados das estimações dos coeficientes de Zipf, Gini e I de Moran para estatísticas de patentes e códigos IPCs

Brasil - 2000-2011

\begin{tabular}{|c|c|c|c|c|c|c|c|c|c|}
\hline \multirow[b]{2}{*}{ Cód. } & \multirow[b]{2}{*}{$\begin{array}{l}\text { Subdomínio } \\
\text { tecnológico }\end{array}$} & \multirow[b]{2}{*}{$\begin{array}{l}\mathrm{N}^{\circ} \\
\text { Reg. }\end{array}$} & \multicolumn{3}{|c|}{ Coeficientes } & \multirow{2}{*}{$\begin{array}{c}\% \text { das } \\
\text { ocorrências } \\
\text { nas top } 10 \\
\text { regiôes }\end{array}$} & \multicolumn{3}{|c|}{ Top 5 regióes em cada tecnologia } \\
\hline & & & Zipf $\left(\mathbf{R}^{2}\right)$ & Gini & $\begin{array}{c}\text { I de } \\
\text { Moran } \\
\text { (P-Valor) }\end{array}$ & & $\begin{array}{c}\text { Class. no } \\
\text { ranking } \\
\text { geral }\end{array}$ & Regiāo & $\begin{array}{c}\text { \% do } \\
\text { total } \\
\text { de } \\
\text { ocorrências }\end{array}$ \\
\hline \multirow{5}{*}{15} & \multirow{5}{*}{ Biotecnologia } & & \multirow{5}{*}{$\begin{array}{c}-1,156^{* * *} \\
(0,973)\end{array}$} & \multirow{5}{*}{0,750} & \multirow{5}{*}{$\begin{array}{l}0,1768 \\
(0,000)\end{array}$} & \multirow{5}{*}{68,69} & 1 & São Paulo (SP) & 20,91 \\
\hline & & & & & & & 2 & Campinas (SP) & 15,04 \\
\hline & & 77 & & & & & 3 & Rio de Janeiro (RJ) & 10,63 \\
\hline & & & & & & & 4 & Belo Horizonte (MG) & 6,92 \\
\hline & & & & & & & 12 & Brasília (DF) & 5,49 \\
\hline \multirow{5}{*}{16} & \multirow{5}{*}{$\begin{array}{l}\text { Produtos } \\
\text { farmacêuticos }\end{array}$} & & \multirow{5}{*}{$\begin{array}{c}-1,170^{* * *} \\
(0,974)\end{array}$} & \multirow{5}{*}{0,715} & \multirow{5}{*}{$\begin{array}{l}0,1189 \\
(0,002)\end{array}$} & \multirow{5}{*}{68,68} & 1 & São Paulo (SP) & 24,72 \\
\hline & & & & & & & 2 & Campinas (SP) & 10,96 \\
\hline & & 102 & & & & & 3 & Rio de Janeiro (RJ) & 7,85 \\
\hline & & & & & & & 4 & Belo Horizonte (MG) & 7,45 \\
\hline & & & & & & & 5 & Curitiba (PR) & 6,35 \\
\hline \multirow{5}{*}{17} & \multirow{5}{*}{$\begin{array}{l}\text { Química } \\
\text { macromolecular, } \\
\text { polímeros }\end{array}$} & & \multirow{5}{*}{$\begin{array}{c}-1,299 * * * \\
(0,948)\end{array}$} & \multirow{5}{*}{0,779} & \multirow{5}{*}{$\begin{array}{l}0,1674 \\
(0,000)\end{array}$} & \multirow{5}{*}{71,96} & 1 & São Paulo (SP) & 22,35 \\
\hline & & & & & & & 3 & Rio de Janeiro (RJ) & 16,36 \\
\hline & & 63 & & & & & 2 & Campinas (SP) & 10,15 \\
\hline & & & & & & & 6 & Porto Alegre (RS) & 9,50 \\
\hline & & & & & & & 19 & São Carlos (SP) & 4,63 \\
\hline \multirow{5}{*}{18} & \multirow{5}{*}{$\begin{array}{l}\text { Química de } \\
\text { alimentos }\end{array}$} & & \multirow{5}{*}{$\begin{array}{c}-1,038^{* * *} \\
(0,990)\end{array}$} & \multirow{5}{*}{0,649} & & & 1 & São Paulo (SP) & 21,85 \\
\hline & & & & & & & 2 & Campinas (SP) & 11,03 \\
\hline & & 104 & & & $\begin{array}{l}0,1692 \\
(0,000)\end{array}$ & 58,62 & 3 & Rio de Janeiro (RJ) & 6,25 \\
\hline & & & & & & & 5 & Curitiba (PR) & 5,97 \\
\hline & & & & & & & 8 & Ribeirăo Preto (SP) & 3,75 \\
\hline & & & & & & & 1 & São Paulo (SP) & 27,47 \\
\hline & & & & & & & 2 & Campinas (SP) & 10,33 \\
\hline 19 & $\begin{array}{l}\text { Química de } \\
\text { materiais }\end{array}$ & 102 & $\begin{array}{c}-1,227^{* * *} \\
(0,981)\end{array}$ & 0,674 & $\begin{array}{l}0,1597 \\
(0,001)\end{array}$ & 67,47 & 3 & Rio de Janeiro (RJ) & 10,22 \\
\hline & & & & & & & 5 & Curitiba (PR) & 6,28 \\
\hline & & & & & & & 4 & Belo Horizonte (MG) & 4,81 \\
\hline & & & & & & & 1 & São Paulo (SP) & 17,62 \\
\hline & & & & & & & 4 & Belo Horizonte (MG) & 17,41 \\
\hline 20 & $\begin{array}{l}\text { Materiais, } \\
\text { metalurgia }\end{array}$ & 82 & $\begin{array}{c}-1,095 \text { *** } \\
(0,955)\end{array}$ & 0,724 & $\begin{array}{l}0,1499 \\
(0,002)\end{array}$ & 63,94 & 2 & Campinas (SP) & 7,70 \\
\hline & & & & & & & 3 & Rio de Janeiro (RJ) & 6,28 \\
\hline & & & & & & & 5 & Curitiba (PR) & 6,06 \\
\hline
\end{tabular}


Hierarquia e concentração na distribuição regional brasileira de invenções...

TABELA 2

Resultados das estimaçôes dos coeficientes de Zipf, Gini e I de Moran para estatísticas de patentes e códigos IPCs

Brasil - 2000-2011

\begin{tabular}{|c|c|c|c|c|c|c|c|c|c|}
\hline \multirow[b]{2}{*}{ Cód. } & \multirow[b]{2}{*}{$\begin{array}{l}\text { Subdomínio } \\
\text { tecnológico }\end{array}$} & \multirow[b]{2}{*}{$\begin{array}{l}\mathrm{N}^{\circ} \\
\text { Reg. }\end{array}$} & \multicolumn{3}{|c|}{ Coeficientes } & \multirow{2}{*}{$\begin{array}{c}\% \text { das } \\
\text { ocorrências } \\
\text { nas top } 10 \\
\text { regiōes }\end{array}$} & \multicolumn{3}{|c|}{ Top 5 regióes em cada tecnologia } \\
\hline & & & $\operatorname{Zipf}\left(\mathbf{R}^{2}\right)$ & Gini & $\begin{array}{c}\text { I de } \\
\text { Moran } \\
\text { (P-Valor) }\end{array}$ & & $\begin{array}{l}\text { Class. no } \\
\text { ranking } \\
\text { geral }\end{array}$ & Regiáo & $\begin{array}{c}\% \text { do } \\
\text { total } \\
\text { de } \\
\text { ocorrências }\end{array}$ \\
\hline \multirow{5}{*}{21} & \multirow{5}{*}{$\begin{array}{l}\text { Tecnologia } \\
\text { de superfície, } \\
\text { revestimentos }\end{array}$} & & \multirow{5}{*}{$\begin{array}{c}-1,152^{* * *} \\
(0,983)\end{array}$} & \multirow{5}{*}{0,738} & \multirow{5}{*}{$\begin{array}{l}0,1646 \\
(0,000)\end{array}$} & \multirow{5}{*}{71,61} & 1 & São Paulo (SP) & 34,56 \\
\hline & & & & & & & 2 & Campinas (SP) & 10,54 \\
\hline & & 66 & & & & & 3 & Rio de Janeiro (RJ) & 5,91 \\
\hline & & & & & & & 5 & Curitiba (PR) & 5,23 \\
\hline & & & & & & & 6 & Porto Alegre (RS) & 4,16 \\
\hline \multirow{5}{*}{22} & \multirow{5}{*}{$\begin{array}{l}\text { Tecnologia das } \\
\text { microestruturas; } \\
\text { nanotecnologia }\end{array}$} & & \multirow{5}{*}{$\begin{array}{c}-1,104^{* * *} \\
(0,928)\end{array}$} & \multirow{5}{*}{0,832} & \multirow{5}{*}{$\begin{array}{l}0,1903 \\
(0,000)\end{array}$} & \multirow{5}{*}{65,35} & 1 & São Paulo (SP) & 25,00 \\
\hline & & & & & & & 4 & Belo Horizonte (MG) & 9,65 \\
\hline & & 28 & & & & & 2 & Campinas (SP) & 9,21 \\
\hline & & & & & & & 19 & São Carlos (SP) & 8,33 \\
\hline & & & & & & & 6 & Porto Alegre (RS) & 7,02 \\
\hline \multirow{5}{*}{$\begin{array}{c}23 \mathrm{e} \\
24\end{array}$} & \multirow{5}{*}{$\begin{array}{l}\text { Engenharia } \\
\text { química e } \\
\text { tecnologia } \\
\text { ambiental }\end{array}$} & & \multirow{5}{*}{$\begin{array}{c}-1,055^{* * *} \\
(0,962)\end{array}$} & \multirow{5}{*}{0,684} & \multirow{5}{*}{$\begin{array}{l}0,1441 \\
(0,003)\end{array}$} & \multirow{5}{*}{65,21} & 1 & São Paulo (SP) & 21,39 \\
\hline & & & & & & & 3 & Rio de Janeiro (RJ) & 12,17 \\
\hline & & 109 & & & & & 2 & Campinas (SP) & 9,23 \\
\hline & & & & & & & 4 & Belo Horizonte (MG) & 7,00 \\
\hline & & & & & & & 6 & Porto Alegre (RS) & 4,11 \\
\hline \multirow{5}{*}{25} & \multirow{5}{*}{ Manipulação } & & \multirow{5}{*}{$\begin{array}{c}-1,116^{* * *} \\
(0,960)\end{array}$} & \multirow{5}{*}{0,715} & & & 1 & São Paulo (SP) & 37,54 \\
\hline & & & & & & & 2 & Campinas (SP) & 7,13 \\
\hline & & 113 & & & $\begin{array}{l}0,1000 \\
(0,038)\end{array}$ & 71,74 & 3 & Rio de Janeiro (RJ) & 6,28 \\
\hline & & & & & & & 5 & Curitiba (PR) & 5,45 \\
\hline & & & & & & & 4 & Belo Horizonte (MG) & 4,16 \\
\hline & & & & & & & 1 & São Paulo (SP) & 24,89 \\
\hline & & & & & & & 2 & Campinas (SP) & 6,90 \\
\hline 26 & $\begin{array}{l}\text { Máquinas, } \\
\text { ferramentas }\end{array}$ & 102 & $\begin{array}{c}-0,968^{* * *} \\
(0,967)\end{array}$ & 0,674 & $\begin{array}{l}0,1541 \\
(0,001)\end{array}$ & 63,22 & 5 & Curitiba (PR) & 6,21 \\
\hline & & & & & & & 4 & Belo Horizonte (MG) & 6,11 \\
\hline & & & & & & & 6 & Porto Alegre (RS) & 5,10 \\
\hline & & & & & & & 1 & São Paulo (SP) & 23,52 \\
\hline & & & & & & & 2 & Campinas (SP) & 8,81 \\
\hline 27 & bombas, & 95 & $\begin{array}{c}-1,095^{* * *} \\
(0,958)\end{array}$ & 0,705 & $\begin{array}{l}0,1777 \\
(0,000)\end{array}$ & 65,65 & 3 & Rio de Janeiro (RJ) & 7,74 \\
\hline & & & & & & & 9 & Joinville (SC) & 7,50 \\
\hline & & & & & & & 4 & Belo Horizonte (MG) & 6,39 \\
\hline
\end{tabular}


TABELA 2

Resultados das estimaçôes dos coeficientes de Zipf, Gini e I de Moran para estatísticas de patentes e códigos IPCs

Brasil - 2000-2011

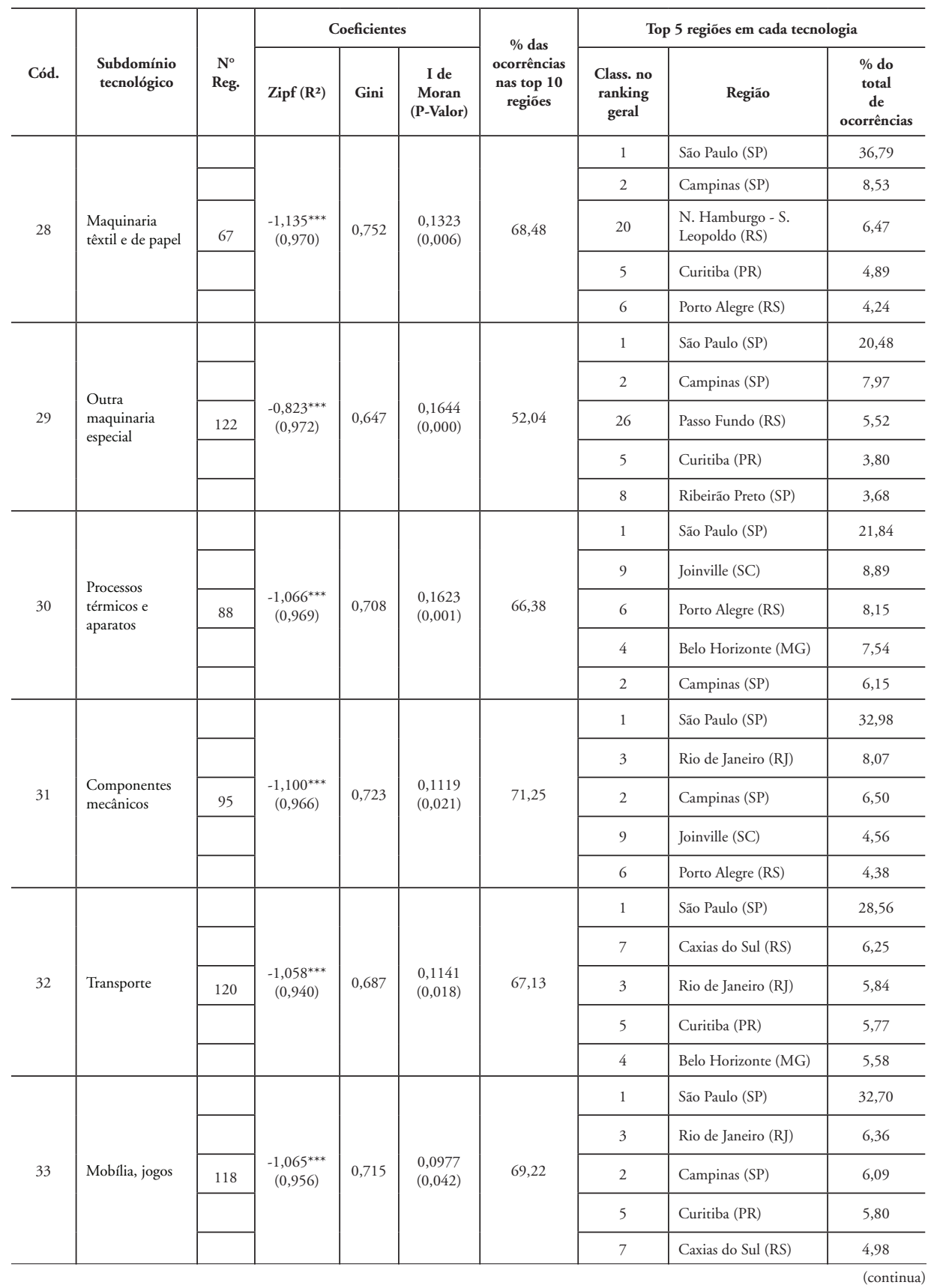


TABELA 2

Resultados das estimaçôes dos coeficientes de Zipf, Gini e I de Moran para estatísticas de patentes e códigos IPCs

Brasil - 2000-2011

\begin{tabular}{|c|c|c|c|c|c|c|c|c|c|}
\hline \multirow[b]{2}{*}{ Cód. } & \multirow[b]{2}{*}{$\begin{array}{l}\text { Subdomínio } \\
\text { tecnológico }\end{array}$} & \multirow[b]{2}{*}{$\begin{array}{l}\mathrm{N}^{\circ} \\
\text { Reg. }\end{array}$} & \multicolumn{3}{|c|}{ Coeficientes } & \multirow{2}{*}{$\begin{array}{c}\% \text { das } \\
\text { ocorrências } \\
\text { nas top } 10 \\
\text { regiōes }\end{array}$} & \multicolumn{3}{|c|}{ Top 5 regióes em cada tecnologia } \\
\hline & & & $\mathrm{Zipf}\left(\mathbf{R}^{2}\right)$ & Gini & $\begin{array}{c}\text { I de } \\
\text { Moran } \\
\text { (P-Valor) }\end{array}$ & & $\begin{array}{c}\text { Class. no } \\
\text { ranking } \\
\text { geral }\end{array}$ & Regiáo & $\begin{array}{c}\% \text { do } \\
\text { total } \\
\text { de } \\
\text { ocorrências }\end{array}$ \\
\hline \multirow{5}{*}{34} & \multirow{5}{*}{$\begin{array}{l}\text { Outros produtos } \\
\text { de consumo }\end{array}$} & & \multirow{5}{*}{$\begin{array}{c}-1,018^{* * *} \\
(0,959)\end{array}$} & \multirow{5}{*}{0,739} & \multirow{5}{*}{$\begin{array}{l}0,1026 \\
(0,033)\end{array}$} & \multirow{5}{*}{70,95} & 1 & São Paulo (SP) & 33,95 \\
\hline & & & & & & & 5 & Curitiba (PR) & 6,50 \\
\hline & & 114 & & & & & 2 & Campinas (SP) & 6,14 \\
\hline & & & & & & & 3 & Rio de Janeiro (RJ) & 6,05 \\
\hline & & & & & & & 6 & Porto Alegre (RS) & 4,62 \\
\hline \multirow{5}{*}{35} & \multirow{5}{*}{$\begin{array}{l}\text { Engenharia } \\
\text { Civil }\end{array}$} & & \multirow{5}{*}{$\begin{array}{c}-1,046^{* * *} \\
(0,982)\end{array}$} & \multirow{5}{*}{0,682} & \multirow{5}{*}{$\begin{array}{l}0,0936 \\
(0,051)\end{array}$} & \multirow{5}{*}{65,54} & 1 & São Paulo (SP) & 28,17 \\
\hline & & & & & & & 3 & Rio de Janeiro (RJ) & 8,23 \\
\hline & & 119 & & & & & 5 & Curitiba (PR) & 6,97 \\
\hline & & & & & & & 4 & Belo Horizonte (MG) & 5,39 \\
\hline & & & & & & & 2 & Campinas (SP) & 4,64 \\
\hline
\end{tabular}

Fonte: Base de Dados Estatísticos de Propriedade Intelectual, Instituto Nacional de Propriedade Intelectual - BADEPI/INPI (versão 1.0). Elaboração dos autores com base em resultados extraídos dos softwares Stata e Geoda.

Todos os ajustes ficaram, em geral, eficientes, o que indica que a relação linear é adequada para expressar a relação entre a classificação e o total de frequências de cada tecnologia. O subdomínio tecnológico com o menor $\mathrm{R}^{2}$ é o 22 (tecnologia de microestruturas e nanotecnologia), com 92,8\%. Certamente isso deve-se a um provável fator quadrático que essa categoria apresenta mediante a distribuição das frequências ao longo da classificação. Excetuando-se esse caso específico, os demais apresentam ajuste linear mais elevado.

O subdomínio tecnológico 29 (outras maquinarias especiais) merece destaque entre os demais por ser o único que efetivamente apresenta um coeficiente hierárquico muito abaixo da média das hierarquias encontradas (0,823 em módulo). Isso não se deve especialmente à baixa participação relativa da região de São Paulo, mas sim a uma participação mais que proporcional das regiōes pior classificadas. A participação das regióes com piores classificações pode ser vista ao se constatar a pequena frequência de IPCs desse subdomínio nas dez maiores regiōes (52,04\%). Isso significa que tal tecnologia pode estar mais dispersa por regióes menores, como Chapecó (SC), Novo Hamburgo (RS), São Leopoldo (RS), Marília (SP) e Araraquara (SP). 
Alguns subdomínios tecnológicos, pelo contrário, se apresentam mais hierarquizados do que a média, como o subdomínio 14 (produtos orgânicos elaborados), que detém mais de $50 \%$ do total das frequências concentradas nas três primeiras regiōes: São Paulo, Campinas e Rio de Janeiro. Outros subdomínios revelam forte concentração hierárquica por São Paulo, como o 7 (métodos de TI para gestão) e o 28 (maquinaria têxtil e de papel), em que a região totaliza 36\% das frequências tecnológicas.

Muitos desses resultados podem ser mais bem visualizados por meio de gráficos do tipo $\log x \log$, contrastando as frequências e a classificação para cada subdomínio tecnológico. Para que sejam padronizados e comparáveis, divide-se o log das variáveis pelo valor máximo assumido pelo $\log$ da variável, tendo assim uma plotagem de dimensão 1 por 1 , de forma que o eixo $Y=\log (" F r e q I P C s ") / \max (\log ($ "Freq IPCs")) e o eixo $X=\log (r a n k) / \max (\log (r a n k))$ Os resultados para os respectivos subdomínios tecnológicos em cada domínio tecnológico estão no Gráfico 1.

É possível notar que, em média, as tecnologias do domínio da engenharia elétrica apresentam uma inclinação maior do que as demais, evidenciando que tal tipo de tecnologia é mais hierarquizada do que a média das demais, o que é natural de se esperar, uma vez que são tecnologias de menor presença no Brasil, de maior sofisticação e de maior participação externa. ${ }^{3}$ Em contraste, os domínios de engenharia mecânica e "outros" apresentam inclinaçôes menores, mostrando graus inferiores de hierarquização, mas ainda assim, hierarquizados, uma vez que se trata de tecnologias mais presentes em menores centros urbanos e de menor sofisticação.

O coeficiente de Gini para as tecnologias se apresenta em um intervalo que vai de 0,647 a 0,832 , sendo o menor a tecnologia 29 (outra maquinaria especial) e a maior a tecnologia 22 (tecnologia de microestruturas; nanotecnologia). Esses extremos são também as tecnologias menos e mais presentes nas regiōes (a primeira, 122 regiōes e a segunda, 28 regiōes). É feito um teste de correlação entre os resultados do coeficiente de Gini e o número total de regiôes detentoras de, ao menos, uma ocorrência de classificação na IPC, apresentando uma correlação de $-81 \%$. Como o Gini mede concentração, é natural assumir que altos coeficientes de Gini explicitarão maior restrição na produção de determinada tecnologia, ou seja, maior concentração das tecnologias em poucas regiōes, e menores coeficientes de Gini o inverso.

3 Segundo o relatório do INPI (Barcelos et al., 2014), 17\% dos depósitos de patentes (5.512 depósitos) advindos de não-residentes no Brasil são do domínio da engenharia elétrica, enquanto nos residentes brasileiros, essa fatia representa 12\% (438 depósitos), para o período 2000-2011. 


\section{GRÁFICO 1}

Distribuição das frequências padronizadas de códigos IPCs, por subdomínios tecnológicos Brasil - 2000-2011

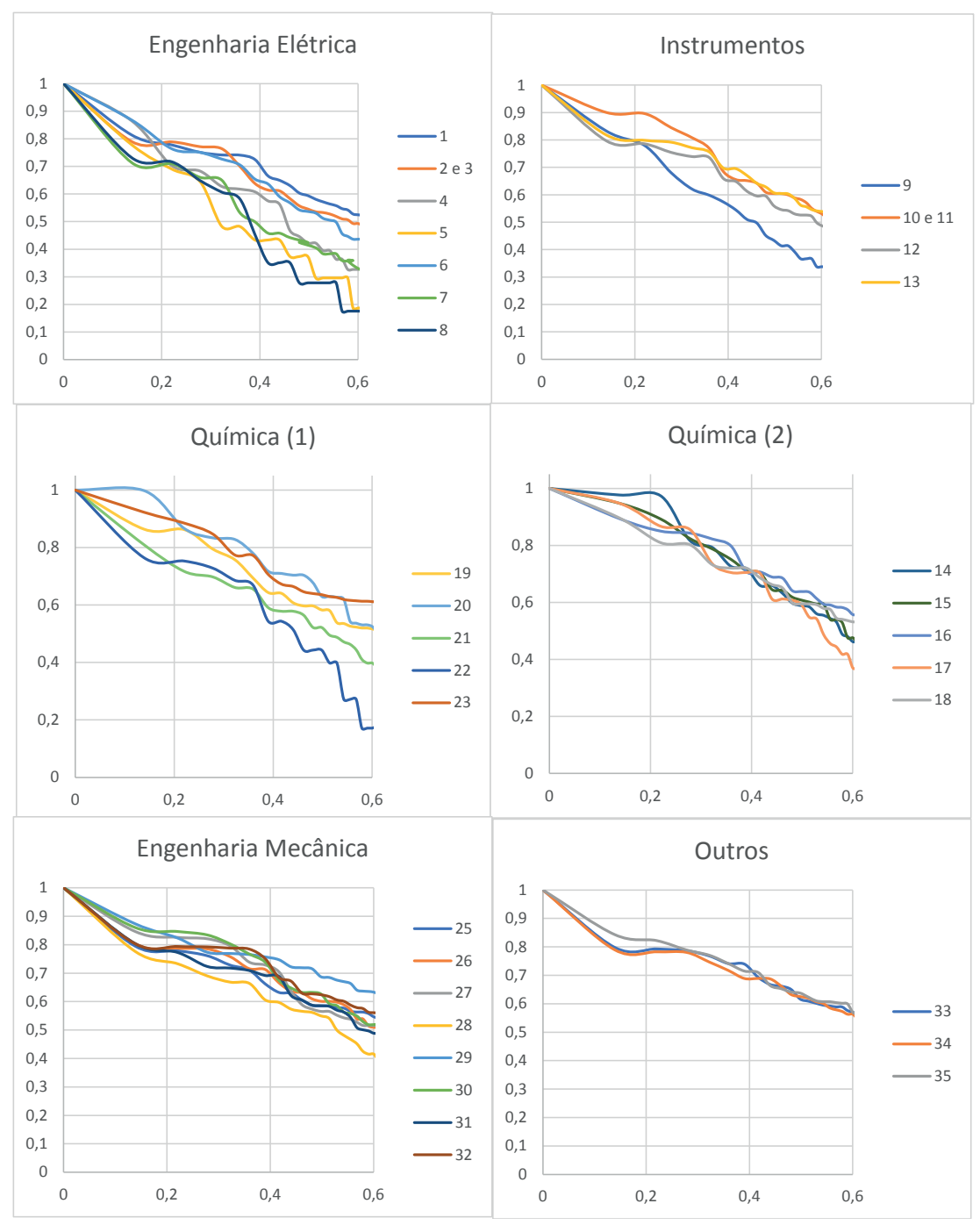

Fonte: Base de Dados Estatísticos de Propriedade Intelectual, Instituto Nacional de Propriedade Intelectual - BADEPI/INPI (versão 1.0). Elaboração dos autores.

Nota: Foi apresentada somente a cauda superior (20 primeiras regiōes).

O coeficiente de hierarquia permite entender como essas tecnologias são processos exclusivos da grande aglomeração, ou se são proporcionalmente distribuídas entre as regiōes menores. A tecnologia menos hierarquizada ("outras maquinarias 
especiais”), por exemplo, é a que possui $28 \%$ do total de frequências de IPCs em São Paulo e Campinas, valor inferior à participação de São Paulo e Campinas em “ótica”, por exemplo, que é de $42 \%$. Além disso, essas duas tecnologias apresentam grandes contrastes: 122 regiōes detêm know-how da primeira, enquanto "ótica” é dominada por um grupo restrito de 52 regiōes, o que também se reflete no coeficiente de Gini de ambas, de 0,647 e 0,758, respectivamente.

Subdomínios tecnológicos de maior sofisticação são restritos espacialmente, mas isso não significa que não possuam presença em regiões urbanas menores. São Carlos (SP), por exemplo, possui mais frequências do que o Rio de Janeiro (RJ) no subdomínio tecnológico de microestruturas e nanotecnologia, o que está relacionado à forte presença de instituições de ensino e pesquisa no interior do Estado de São Paulo (SUZIGAN et al., 2006). Em síntese, os resultados podem ser agrupados como mostrado no Quadro 2. ${ }^{4}$

Os grupos podem ser descritos da seguinte forma:

I hierarquia acima da média e alta concentração - refere-se aos subdomínios tecnológicos de maior sofisticação dos grandes centros urbanos, sendo não só restritos a um número pequeno de regiōes, como também predominantes nos maiores centros urbanos;

II hierarquia acima da média e concentração - subdomínios tecnológicos predominantes nos maiores centros urbanos, mas que possuem maior frequência nos centros urbanos menores;

III hierarquia abaixo da média e alta concentração - subdomínios tecnológicos proporcionalmente mais bem distribuídos entre os principais centros urbanos e que não são muito presentes nos menores centros urbanos;

IV hierarquia abaixo da média e concentração - subdomínios tecnológicos de menor sofisticação tecnológica, que são compostos principalmente pelos grandes centros urbanos, mas que possuem maior participação dos médios e pequenos centros urbanos, sendo tecnologias essenciais para o entendimento dos processos de aproximação da fronteira tecnológica das áreas urbanas com potencial inovador por meio de conhecimentos mais acessíveis. É importante ressaltar que o subdomínio tecnológico é hierarquizado e concentrado, o que implica alta predominância na atividade pelos grandes centros urbanos e em alta concentração dessa atividade em poucas regiões.

4 A título de comparação o coeficiente de Zipf calculado para proxies de capacidade de P\&D industrial e universitária, medidos, respectivamente, por pessoal ocupado em profissões técnico-científicas, conforme o trabalho de Araújo, Cavalcante e Alves (2009), e professores doutores de áreas de formação tecnológica (Engenharias, Análises de Sistemas, Biológicas, Química e Física) é de $-1,216$ e $-0,891$. 


\section{QUADRO 2}

Agrupamento dos subdomínios tecnológicos de acordo com os resultados dos coeficientes de Zipf e Gini

Brasil - 2000-2011

\begin{tabular}{|c|c|c|}
\hline Hierarquia & $\begin{array}{l}\text { Gini acima da média (altamente } \\
\text { concentrado) }\end{array}$ & $\begin{array}{l}\text { Gini abaixo da média } \\
\text { (concentrado) }\end{array}$ \\
\hline $\begin{array}{l}\text { Hierarquia acima } \\
\text { da média }\end{array}$ & $\begin{array}{l}\text { Comunicação digital (4); tecnologia } \\
\text { de computadores (6); métodos de TI } \\
\text { p/ gestão (7); ótica (9); prod. orgân. } \\
\text { elaborados (14); biotecnologia (15); } \\
\text { química macromolecular, polímeros } \\
\text { (17); tecnologia de superfície, } \\
\text { revestimentos (21); tecnologia das } \\
\text { microestruturas; nanotecnologia (22); } \\
\text { maquinaria têxtil e de papel (28) }\end{array}$ & $\begin{array}{l}\text { Maquinaria elétrica e aparatos, } \\
\text { energia elétrica (1); tecnologia } \\
\text { audiovisual e telecomunicaçôes ( } 2 \\
\text { e 3); medição e análise de materiais } \\
\text { biológicos (10 e 11); tecnologia } \\
\text { médica (13); produtos farmacêuticos } \\
\text { (16); química de materiais (19); } \\
\text { manipulação (25) }\end{array}$ \\
\hline $\begin{array}{l}\text { Hierarquia abaixo } \\
\text { da média }\end{array}$ & $\begin{array}{l}\text { Processo de comunicação básica } \\
\text { (5); semicondutores (8); materiais, } \\
\text { metalurgia (20); componentes } \\
\text { mecânicos (31); outros produtos de } \\
\text { consumo (34) }\end{array}$ & $\begin{array}{l}\text { Controle (12); química de alimentos } \\
\text { (18); eng. química e tecnologia } \\
\text { ambiental ( } 23 \text { e } 24) \text {; máquinas, } \\
\text { ferramentas (26); motores, bombas, } \\
\text { turbinas ( } 27) \text {; outra maquinaria } \\
\text { especial (29); processos térmicos e } \\
\text { aparatos (30); transporte (32); } \\
\text { mobília, jogos (33); engenharia civil } \\
(35)\end{array}$ \\
\hline
\end{tabular}

Fonte: Base de Dados Estatísticos de Propriedade Intelectual, Instituto Nacional de Propriedade Intelectual - BADEPI/INPI (versão 1.0). Elaboração dos autores.

Nota: As médias dos coeficientes de Zipf e de Gini são -1,10 e 0,72, respectivamente.

Com o intuito de verificar se os resultados diferem quando se analisam apenas as patentes de alta tecnologia, foi construído um agrupamento de códigos IPCs com os principais códigos de tecnologias de computadores, biotecnologia, semicondutores e telecomunicações (Tabela 3), seguindo classificação da Organisation for Economic Co-operation and Development - OECD (EUROSTAT, 2016). ${ }^{5}$ Os resultados indicam que não houve redução dos graus de hierarquia para abaixo da média com a agregação, indicando que a hierarquia das patentes de alta tecnologia pertence aos quadrantes superiores do Quadro 2. Ou seja, no caso das patentes de alta tecnologia, o coeficiente de Zipf reflete uma hierarquia acima da média na cauda superior, isto

5 Os códigos de patentes (IPC a 4 dígitos) de alta tecnologia são: B41J, G06C, G06D, G06E, G11C, G06Q, G06G, G06J, G06F, G06M, B64B, B64C, B64D, B64F, B64G, C40B, C12P, C12Q, H01S, H01L, H04B, H04H, H04J, H04L, H04M, H04N, H04Q, H04R, H04S, A01H, A61K, C02F, C12N, C12P, C12Q, C12S, G01N (EUROSTAT, 2016). 
é, a maior predominância das regiōes do topo, principalmente São Paulo, sobre as demais regiôes. O coeficiente de Gini, entretanto, se apresenta abaixo da média, indicando maior participação relativa de regiôes menores na distribuição total. Com isso, as patentes de alta tecnologia se enquadrariam no grupo de hierarquia acima da média e concentração abaixo da média.

\section{TABELA 3}

Resultados das estimaçôes dos coeficientes de Zipf, Gini e I de Moran para patentes de alta tecnologia Brasil - 2000-2011

\begin{tabular}{lc}
\hline \multicolumn{1}{c|}{ Estatística } & Patentes de alta tecnologia \\
\hline Coeficiente de Zipf (R $\left.{ }^{2}\right)$ & $-1,175^{* * *}$ \\
Coeficiente de Gini & $(0,990)$ \\
I de Moran (P-valor) & 0,702 \\
\% das ocorrências nas top 10 regiōes & 0,1226 \\
& $0,003)$ \\
\% das ocorrências nas Top 5 Regiões & 71,29 \\
São Paulo (SP) & 26,19 \\
Campinas (SP) & 11,59 \\
Rio de Janeiro (RJ) & 8,21 \\
Belo Horizonte (MG) & 6,86 \\
Curitiba (PR) & 5,61 \\
\hline
\end{tabular}

Fonte: Base de Dados Estatísticos de Propriedade Intelectual, Instituto Nacional de Propriedade Intelectual - BADEPI/INPI (versão 1.0). Elaboração dos autores.

\subsection{Clusters espaciais de invenções}

O I de Moran revela padrôes de autocorrelação espacial significativos, ao menos ao nível de 10\%, para todos os subdomínios tecnológicos. A matriz de pesos espaciais escolhida foi a de K-vizinhos, sendo a métrica utilizada a distância euclidiana, de acordo com o critério de Baumont et al. (2004). Os pesos da matriz de K-vizinhos permitem capturar o problema da heterogeneidade no tamanho das regiōes de influência das cidades do Brasil. Foram feitos testes para contiguidade, distância e $\mathrm{K}$-vizinhos, e os resultados apontam que a matriz de $\mathrm{K}$-vizinhos com $\mathrm{K}=6$ é a que apresenta os menores p-valores e os melhores coeficientes de todos os I de Moran calculados. 
As regiôes contíguas de São Paulo e Campinas formam uma aglomeração de potencial inovador em todas as tecnologias. A ausência de aleatoriedade espacial e o padrão de autocorrelação espacial positivo (concentração) das invenções nas tecnologias e, principalmente, a evidência de que há distinções nos padrões de aglomeração para cada tecnologia revelam alguns aspectos interessantes. Quanto maior o I de Moran, maior é a dependência espacial da tecnologia, o que pode revelar maior força de transbordamentos espaciais. Na Figura 2, observa-se o padrão de clusters de subdomínios tecnológicos selecionados ${ }^{6}$ dos quadrantes I e IV dos agrupamentos de hierarquia e concentração.

A maior presença de regiōes com padrão não significativo é reflexo da baixa média de ocorrências dessas tecnologias. Como o I de Moran local baseia-se nas variáveis padronizadas (o $z$ da equação 7), os valores das ocorrências são comparados com a média de todas as regiôes, sendo que a não significância indica que tal região não se encontra em nenhum agrupamento porque o valor da variável para essa região não é distinto, estatisticamente, da média das regiōes (ANSELIN, 1988). As médias dos subdomínios 7 e 9 são, respectivamente, 3,85 e 4,12, enquanto as médias dos grupos 32 e 29 são 47,8 e 51,5, respectivamente. A média relativamente baixa dos subdomínios tecnológicos do quadrante I dificilmente permite a identificação de clusters do tipo baixo-baixo, sendo predominante o baixo número de ocorrências em todo o Brasil, excetuando-se as regiões do eixo Rio-São Paulo-Campinas. Em geral, os subdomínios tecnológicos do quadrante IV permitem a identificação de clusters do tipo baixo-baixo em regiōes do Norte e do Nordeste. Destaca-se que, em geral, a região de Fortaleza se separa do padrão baixo-baixo nordestino, apresentando cluster do tipo baixo-alto em 21 subdomínios.

Esses resultados são refletidos no I de Moran global por meio da magnitude dos coeficientes de autocorrelação espacial. O maior valor do I de Moran global $(0,21)$ se encontra no subdomínio tecnológico 4 comunicação digital (quadrante I), enquanto o menor valor $(0,09)$ pertence ao subdomínio tecnológico 35 (quadrante IV). Os subdomínios tecnológicos com I de Moran global mais alto (Tabela 2) são também aqueles mais hierarquizados e concentrados do que a média (subdomínios 4, 9, 22, 6 e 14). Apesar disso, o padrão não sugere que as tecnologias menos hierarquizadas e menos concentradas do que a média sejam também menos aglomeradas espacialmente do que a média. Tecnologias como motores (27) e química de alimentos (18) são mais aglomeradas do que a média, mas não são tão hierarquizadas e são mais bem distribuídas do que a média.

6 Os demais mapas encontram-se no apêndice B. 
FIGURA 2

Mapas de clusters espaciais para os subdomínios tecnológicos selecionados - 2000-2011
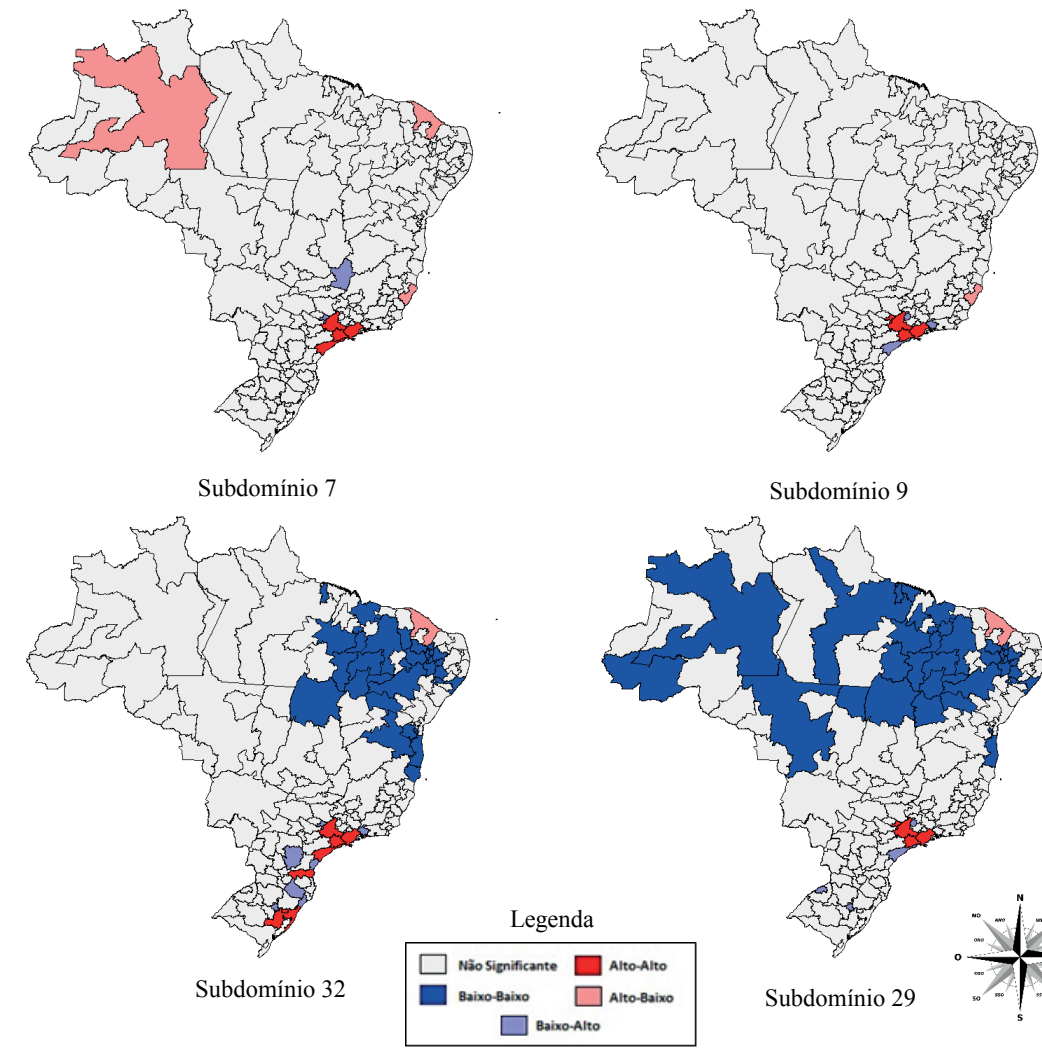

Subdomínio 9

3

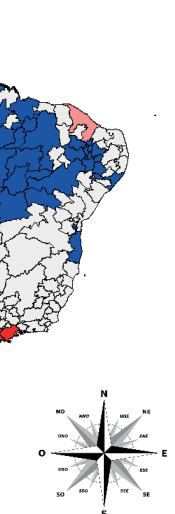

Fonte: Base de Dados Estatísticos de Propriedade Intelectual, Instituto Nacional de Propriedade Intelectual - BADEPI/INPI (versão 1.0). Elaboração dos autores a partir do software Open GeoDa.

\section{Conclusões}

Esse artigo investigou a distribuição espacial da atividade tecnológica brasileira, medida por dados de depósitos de patentes, segundo a localização dos seus inventores. Para tal, foram usados diversos códigos (classes tecnológicas) presentes nos registros do total de depósitos de patentes do período 2000-2011, identificando a posição relativa de cada região brasileira segundo sua especialidade tecnológica. Diferentes medidas de concentração são combinadas para revelar o nível de desigualdade, de hierarquia e de agrupamento espacial de diferentes subcategorias tecnológicas no sistema de inovação brasileiro, analisado por regiōes de influência. 
O coeficiente de Gini revelou, de modo geral, alto nível de concentração das subcategorias tecnológicas por regiōes inventivas. $\mathrm{O}$ menor e o maior coeficientes foram, respectivamente, 0,647 (subdomínio 29, outras maquinarias especiais) e 0,832 (subdomínio 22, tecnologias de microestruturas e nanotecnologia). As dez principais regiões no subdomínio 29 concentravam 52\% do total de frequência de códigos de patentes nessa tecnologia. Mesmo que seja mais ubíqua, essa tecnologia possui também regiōes dominantes, como São Paulo, que possui mais de $20 \%$ das frequências dessa tecnologia, em relação aos aproximadamente $8 \%$ de Campinas. No caso da tecnologia 22, as dez principais regiōes concentravam 65\% dos códigos. São Paulo possuía participação maior que $25 \%$, enquanto Belo Horizonte e Campinas pouco mais de $9 \%$.

O coeficiente de I de Moran revelou que a distribuição espacial das competências tecnológicas regionais não é aleatória no Brasil, indicando a existência de agrupamentos espaciais de subcategorias tecnológicas. Esse resultado pode indicar a existência de clusters espaciais de tecnologias que dependem de fluxos de conhecimento mediados pela distância geográfica, na medida em que os dados de códigos de patentes revelam dependência espacial positiva. Ressalta-se que o padrão não sugere que as tecnologias menos hierarquizadas e menos concentradas do que a média sejam também menos aglomeradas do que a média. Em outras palavras, não há uma grande correlação entre as medidas de hierarquia e aglomeração espacial $(-11,78 \%)$ e entre as medidas de concentração e aglomeração espacial $(27,13 \%)$, apesar de existir uma maior correlação entre hierarquia e concentração (-45,8\%).

Com base nos coeficientes de Zipf para a cauda superior do sistema inventivo brasileiro, composto pelas 20 regiōes mais inventivas, notaram-se níveis variáveis de hierarquização. Algumas tecnologias, como outra maquinaria especial (29), processos de comunicação básica (5), máquinas e ferramentas (26), outros produtos de consumo (34) e química de alimentos (18), são menos hierarquizadas, enquanto outras, como química macromolecular e polímeros (17), produtos orgânicos elaborados (14), química de materiais (19), tecnologia audiovisual e telecomunicaçôes (2 e 3) e ótica (9), estão entre as mais hierarquizadas no Brasil. No caso da subcategoria tecnológica química de alimentos (19), São Paulo possui 21,85\% das frequências de códigos dessa tecnologia, proporção duas vezes superior à de Campinas ou três vezes maior do que a do Rio de Janeiro.

Os mapas de aglomeração espacial (Apêndice Brevelam a predominância da aglomeração espacial do eixo Rio-São Paulo-Campinas em todos os domínios tecnológicos. São Carlos aparece como um "alto-alto" juntamente a esse eixo em 19 mapas de aglomeração. O Sul do país apresenta padrões de agrupamento do tipo 
"alto-alto" em subdomínios específicos (27, 28, 30 e 32), destacando-se Joinville, Blumenau, Porto Alegre e Novo Hamburgo. O Centro-Oeste do País, em geral, não apresenta agrupamentos espaciais significativos, com base no I de Moran Local, excetuando-se a região de Goiânia na tecnologia 22, sendo um agrupamento do tipo "alto-baixo". O Norte e o Nordeste geralmente apresentam padrão "baixo-baixo" nas tecnologias menos concentradas, e agrupamentos não significativos nas tecnologias mais concentradas. Destacam-se os casos particulares em que a região de Fortaleza aparece como um "alto-baixo" em 21 mapas. No Norte, Belém e Manaus se destacam em agrupamentos do tipo "alto-baixo" em cinco e três subdomínios tecnológicos, respectivamente.

A utilização das três medidas fornece, portanto, uma análise descritiva minuciosa dos subdomínios tecnológicos do sistema brasileiro de invenções e sua distribuição espacial sob um olhar que contempla a hierarquia, a concentração e a aglomeração espacial. A hierarquia urbana possui regularidade empírica prevista pela Lei de Zipf e a concentração espacial das invençôes sugere a existência de fluxos de conhecimento localizados, destacando o papel central do eixo Rio-São Paulo-Campinas. Algumas tecnologias são menos concentradas e contam com maior participação de centros urbanos menores. Outras tecnologias parecem estar associadas a regiōes que desenvolvem atividades industriais específicas, como a região de São Carlos e outras do Sul do Brasil.

Do ponto de vista das políticas públicas locais, as evidências trazidas sugerem que, em algumas tecnologias, a aquisição de competências tecnológicas por regiōes é mais plausível. Isso se dá em tecnologias mais ubíquas, como os mobiliários, engenharias civil e mecânica. Por outro lado, no caso de tecnologias mais sofisticadas, como as elétrica-eletrônicas, nano e biotecnologias, é custoso superar a posição conquistada por regiōes de mais elevada centralidade urbana, como São Paulo, Rio de Janeiro, Campinas, Belo Horizonte e Curitiba. Do ponto de vista de políticas públicas nacionais, a desproporção encontrada em coeficientes de hierarquia elevados indica a polarização dos grandes centros urbanos. Se há interesse em reduzir a desigualdade regional da atividade inventiva no Brasil, contemplando as diferenças de escala urbana entre as regiôes, devem-se focalizar os investimentos nas regiōes mais hierarquizadas e em tecnologias mais hierarquizadas, com o intuito de reduzir sua distância para as regiōes urbanas centrais.

Os resultados encontrados estão sujeitos a limitações metodológicas, como a impossibilidade de compreender os efeitos da hierarquia urbana sobre regióes muito pequenas, ou seja, o tratamento da "cauda-inferior", que representam regiōes que patenteiam pouco ou nada. 
Hierarquia e concentração na distribuição regional brasileira de invenções...

\section{Referências bibliográficas}

ACS, Z. J.; ANSELIN, L.; VARGA, A. Patents and innovation counts as measures of regional production of new knowledge. Research Policy, v. 31, n. 7, p. 1069-1085, 2002.

ALBUQUERQUE, E. da M. Domestic patents and developing countries: arguments for their study and data from Brazil (1980-1995). Research Policy, v. 29, n. 9, p. 1047-1060, 2000.

ANSELIN, L. Spatial econometrics: methods and models. Springer Science \& Business Media, 1988.

Local indicators of spatial association - LISA. Geographical Analysis, v. 27, n.

2, p. 93-115, 1995.

ARAÚjO, V. de C. Dimensão local da inovação no Brasil: determinantes e efeitos de proximidade. 2014. 188 f. Tese (Doutorado em Engenharia de Produção) - Escola Politécnica, Universidade de São Paulo, São Paulo, 2014.

ARAÚJO, V. de C.; GARCIA, R. Local determinants of innovation and spatial dependence - A Spatial Tobit model applied to Brazilian Micro-regions. In: $42^{\circ}$ ENCONTRO NACIONAL DE ECONOMIA. Anais... Natal: Anpec, 2014.

ARAÚJO, B. C.; CAVALCANTE, L. R.; ALVES, P. Variáveis proxy para os gastos empresariais em inovação com base no pessoal ocupado técnico-científico disponível na Relação Anual de Informações Sociais (RAIS). Radar: tecnologia, produção e comércio exterior, v. 5, p. 16-21, 2009.

AUDRETSCH, D. B.; FELDMAN, M. P. R\&D spillovers and the geography of innovation and production. The American Economic Review, v. 86, n. 3, p. 630-640, 1996.

AUDRETSCH, D. B.; STEPHAN, P. E. Company-scientist locational links: the case of biotechnology. The American Economic Review, v. 86,n. 3, p. 641-652, 1996.

BARCELOS, V; et al. The use of intellectual property in Brazil. World Intellectual Property Organization, 2014 (Economic Research Working Paper, n. 23).

BAUMONT, C.; ERTUR, C.; GALLO, J. Spatial analysis of employment and population density: the case of the agglomeration of Dijon 1999. Geographical Analysis, v. 36, n. 2, p. 146-176, 2004.

CARLINO, G. A., CHATTERJEE, S.; HUNT, R. M. Urban density and the rate of invention. Journal of Urban Economics, v. 61, n. 3, p. 389-419, 2007.

CARLINO, G,; KERR, W, R. Agglomeration and innovation. National Bureau of Economic Research, 2014. 
CEH, B. Regional innovation potential in the United States: evidence of spatial transformation. Papers in Regional Science, v. 80, n, 3, p. 297-316, 2001.

CHRISTALLER, W. Central places in southern Germany. Englewood Cliffs, NJ: PrenticeHall, 1966.

DINIZ, C. C.; GONÇALVES, E. Economia do conhecimento e desenvolvimento regional no Brasil. In: DINIZ, C. C.; LEMOS, M. B. (Org.). Economia e território. 1. ed. Belo Horizonte: UFMG, 2005. p. 131-170.

EUROSTAT. High-tech industry and knowledge intensive services (htec). 2016. Disponível em <http://ec.europa.eu/eurostat/cache/metadata/DE/htec_esms.htm>. Acesso em: 12 set. 2016.

FELDMAN, M. P. The new economics of innovation, spillovers and agglomeration: a review of empirical studies. Economics of Innovation and New Technology, v. 8, n. 1-2, p. 5-25, 1999. FELDMAN, M. P.; FLORIDA, R. The geographic sources of innovation: technological infrastructure and product innovation in the United States. Annals of the Association of American Geographers, v. 84, n. 2, p. 210-229, 1994.

FUJITA, M.; KRUGMAN, P. R.; VENABLES, A. J. The spatial economy: cities, regions, and international trade. Cambridge, MA, London, England: MIT Press, 2001.

GARCIA, R. Geografia da inovação. In: RAPINI, M. S.; SILVA, L. A.; ALBUQUERQUE, E. da M. (Org.). Economia da ciência, tecnologia e inovação. População e Economia (UFMG), 2016.

GLAESER E. L.; KALLAL, H. D.; SCHEINKMAN, J. A.; SHLEIFER, A. Growth in cities. Journal of Political Economy, v. 100, n. 6, p. 1126-1152, 1992.

GÓIS SOBRINHO, E. M. G.; AZZONI, C. R. Potencial inovativo da indústria nas regiōes brasileiras. Revista Brasileira de Inovação, v. 15, n. 2, p. 275-304, jul./dez. 2016.

GONÇALVES, E. O padrão espacial da atividade inovadora brasileira: uma análise exploratória. Estudos Econômicos (São Paulo), v. 37, n. 2, p. 405-433, 2007.

GONÇALVES, E.; ALMEIDA, E. Innovation and spatial knowledge spillovers: evidence from Brazilian patent data. Regional Studies, v. 43, n. 4, p. 513-528, 2009.

GONÇALVES, E.; LEMOS, M, B,; NEGRI, J, A, de. The role of firm and territory in innovative activities in Brazilian post-opening economy. Economia Aplicada, v. 15, n. 1, p. 103-130, 2011.

GUERRIERO, V. Power law distribution: method of multi-scale inferential statistics. Journal of Modern Mathematics Frontier, v. 1,n. 1, p. 21-28, 2012.

HIGGS, R. American inventiveness, 1870-1920. The Journal of Political Economy, v. 79, n. 3, p. 661-667, 1971. 
Hierarquia e concentração na distribuição regional brasileira de invenções...

HOLMES, T. J.; LEE, S. Cities as six-by-six-mile squares: Zipf's law? Agglomeration Economics. Chicago, IL: University of Chicago Press, 2010. p. 105-131.

HSU, W.-T. Central place theory and city size distribution. The Economic Journal, v. 122, n. 563, p. 903-932, 2012.

IBGE - Instituto Brasileiro de Geografia e Estatística. Regiōes de influência das cidades 2007. Rio de Janeiro, 2008.

Divisão urbano-regional. Rio de Janeiro, 2013.

Arranjos populacionais e concentrações urbanas no Brasil. Rio de Janeiro, 2015.

JAFFE, A. B. Real effects of academic research. The American Economic Review, v. 79, n. 5, p. 957-970, 1989.

JAFFE, A.; TRAJTENBERG, M. HENDERSON, R. M.; Geographic localization of knowledge spillovers as evidenced by patent citations. The Quarterly Journal of Economics, v. 108, n. 3, p. 578-598, 1993.

JOHANSSON, B. Generation and diffusion of innovation. In: FISCHER, M. M. Handbook of regional science. Heidelberg: Springer, 2014.

KRUGMAN, P. R. Geography and trade. Cambridge, MA: MIT Press, 1991.

LE GALLO, J.; CHASCO, C. Spatial analysis of urban growth in Spain, 1900-2001. Empirical Economics, v. 34, n. 1, p. 59-80, 2008.

LEMOS, M. B.; CAMPOS, B.; BIAZI, E.; SANTOS, F. Capacitação tecnológica e catching up: o caso das regiōes metropolitanas emergentes brasileiras. Revista de Economia Política, v. 26, n. 1, p. 95-118, 2006.

LESAGE, J. P. Spatial econometrics. Regional research institute. Morgantown, WV: West Virginia Univ., 1999.

MALISZEWSKI, P. J.; HUALLACHAIN, B. O. Hierarchy and concentration in the American urban system of technological advance. Papers in Regional Science, v. 91, n. 4, p. 743-758, 2012.

MARSHALL, A. Princípios de economia. São Paulo: Nova Cultural, 1983 (Os Economistas).

MASCARINI, S. Fatores territoriais da inovação: uma análise empírica das relaçôes entre os insumos inovativos e os resultados da inovação aplicada às microrregiôes paulistas. Dissertação (Mestrado) - Instituto de Geociências - Universidade Estadual de Campinas - Unicamp, Campinas, 2012.

MCCANN, P.. Schools of thought on economic geography, institutions, and development. In: FISCHER, M. M. Handbook of regional science. Heidelberg: Springer, 2014. 
MONTENEGRO, R. L.; GONÇALVES, E.; ALMEIDA, E. Dinâmica espacial e temporal da inovação no estado de São Paulo: uma análise das externalidades de diversificação e especialização. Estudos Econômicos (São Paulo), v. 41, n. 4, p. 743-776, 2011.

MORENO, R.; PACI, R.; USAI, S. Spatial spillovers and innovation activity in European regions. Environment and Planning A, v. 37, p. 1793-1812, 2005.

MUKIM, M. Does agglomeration boost innovation? An econometric evaluation. Spatial Economic Analysis, v. 7, n. 3, p. 357-380, 2012.

MULLIGAN, G. F. Agglomeration and central place theory: a review of the literature. International Regional Science Review, v. 9, n. 1, p. 1-42, 1984.

NAKAMURA, R.; PAUL, C. J. M. Measuring agglomeration. In: CAPELLO, R.; NIJKAMP, P. (Ed.). Handbook of regional growth and development theories. Cheltenham, UK; Northampton, MA: Edward Elgar Publishing, 2010.

NEWMAN, M. E. J. Power laws, Pareto distributions and Zipf's law. Contemporary Physics, v. 46, n. 5, p. 323-351, 2005.

OHLIN, B. International and interregional trade. Harvard Economic Studies, Cambridge, MA: Harvard University Press, 1933.

O’HUALLACHÁIN, B. Patent places: size matters. Journal of Regional Science, v. 39, n. 4, p. 613-636, 1999.

RUIZ, R. M. Estruturas urbanas comparadas: Estados Unidos e Brasil. Estudos Econômicos (São Paulo), v. 35, n. 4, p. 715-737, 2005.

SCHMOCH, U. Concept of a technology classification for country comparisons. Final report to the world intellectual property organization (WIPO). WIPO, 2008.

SIMŌES, R. F. et al. Centralidades e hierarquia urbana em Minas Gerais: uma visão prospectiva. In: XIV SEMINÁRIO SOBRE A ECONOMIA MINEIRA. Anais... Belo Horizonte: Cedeplar, Universidade Federal de Minas Gerais, 2010.

SIMMIE, J. Innovative cities. New York: Routledge, 2003a.

. Innovation and urban regions as national and international nodes for the transfer and sharing of knowledge. Regional Studies, v. 37, n. 6-7, p. 607-620, $2003 \mathrm{~b}$.

SUZIGAN, W.; FURTADO, J.; GARCIA, R.; SAMPAIO, S. E. K. Inovação e conhecimento: indicadores regionalizados e aplicação a São Paulo. Revista de Economia Contemporânea, v. 10, n. 2, p. 323-356, 2006.

WIPO - World International Pattent Office. International Patent Classification (IPC). Disponível em: <http://www.wipo.int/classifications/ipc/en/>. Acesso em: 16 jun. 2015. 


\section{APÊNDICE A}

FIGURA A1

Evolução temporal das ocorrências de IPCs para os domínios tecnológicos no Brasil (2000-2011)

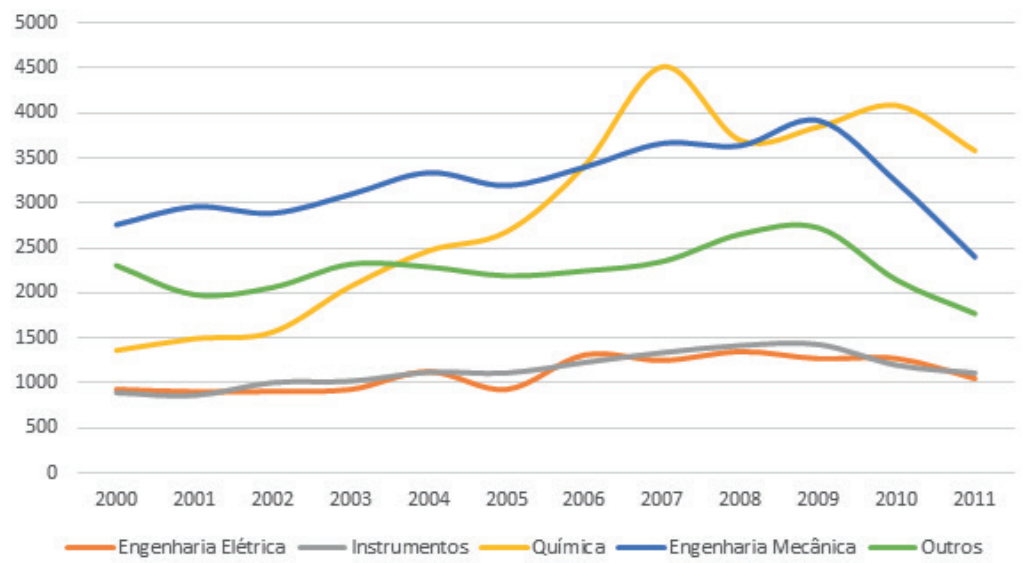

Fonte: Elaboração própria com base em dados da BADEPI/INPI (Versão 1.0)

FIGURA A2

Evolução temporal das ocorrências de IPCs para as cinco principais regiōes patenteadoras do Brasil (2000-2011)

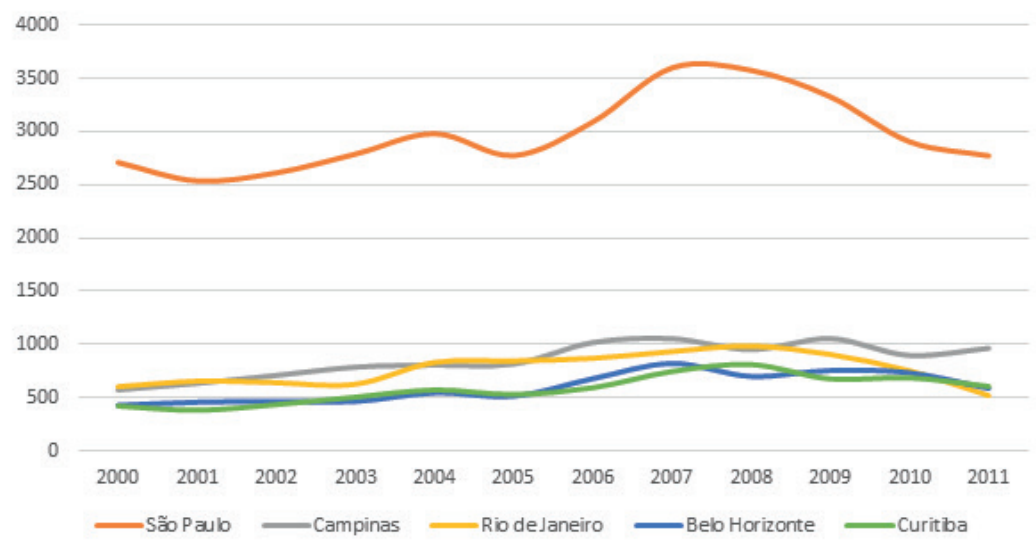

Fonte: Elaboração própria com base em dados da BADEPI/INPI (Versão 1.0) 
FIGURA A3

Evolução temporal das ocorrências de IPCs para as 20 principais regiōes patenteadoras do Brasil e as demais 141 regióes (período 2000-2011)

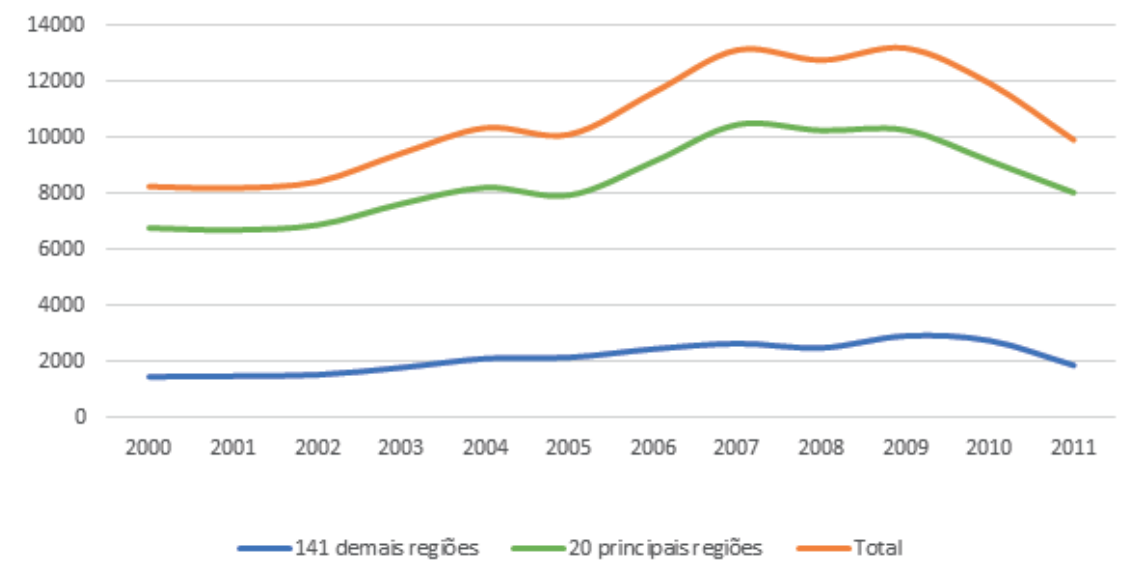

Fonte: Elaboração própria com base em dados da BADEPI/INPI (Versão 1.0) 


\section{APÊNDICE B}

MAPAS DE CLUSTERS CALCULADOS PELO I DE MORAN LOCAL PARA OS 35 SUBDOMÍNIOS TECNOLÓGICOS AO NÍVEL DE REGIÔES INTERMEDIÁRIAS

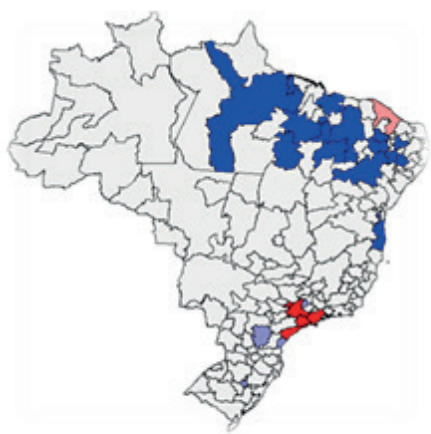

Subdominio 1

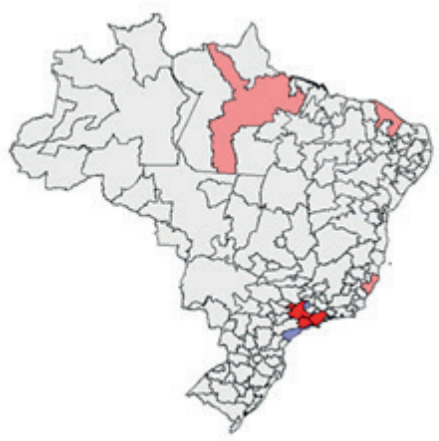

Subdominio 4

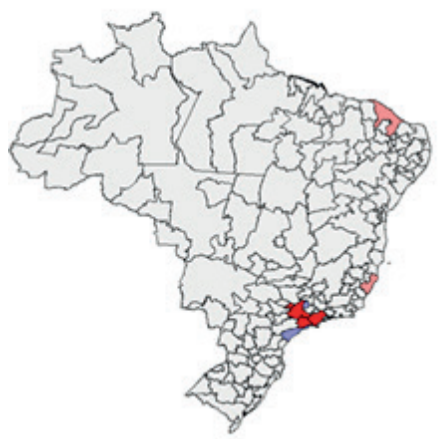

Subdominio 6

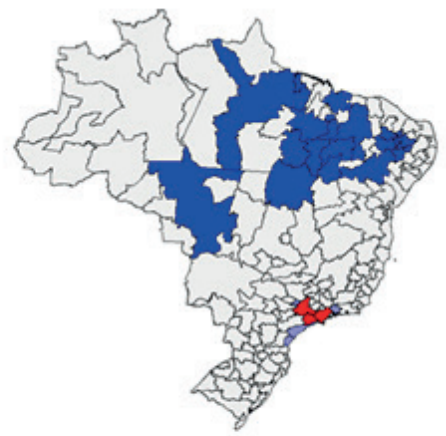

Subdominio 2 e 3

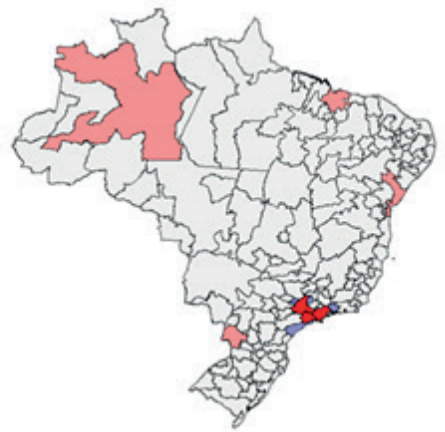

Subdominio 5

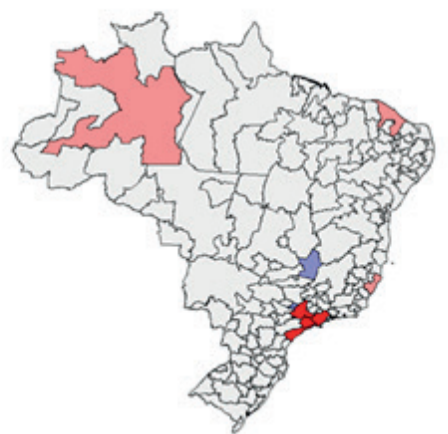

Subdomínio 7

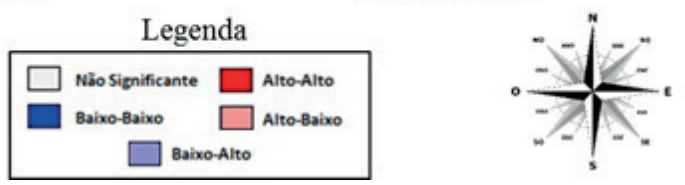




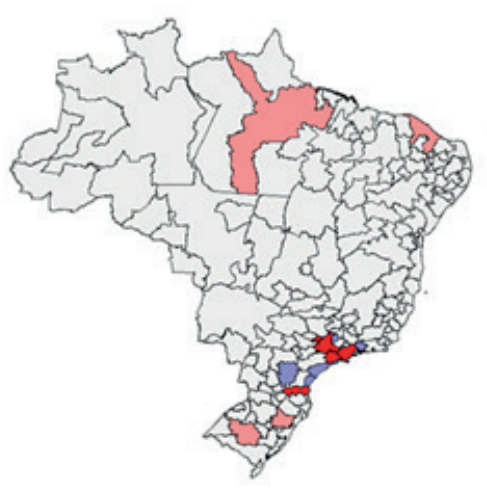

Subdominio 8

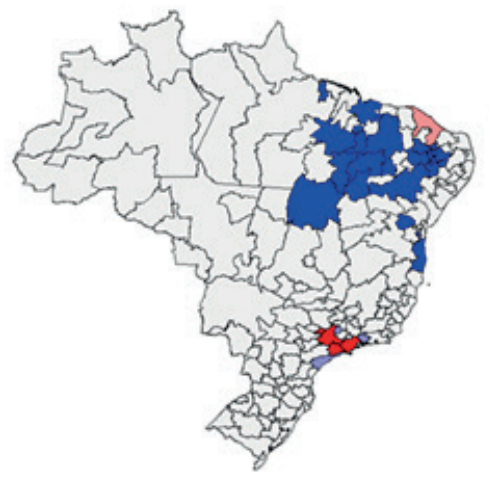

Subdomínio 10 e 11

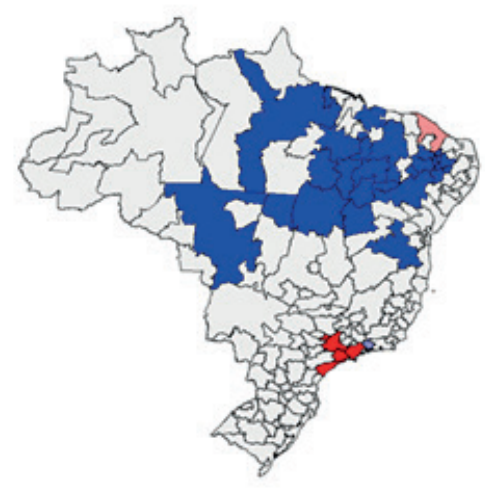

Subdominio 13

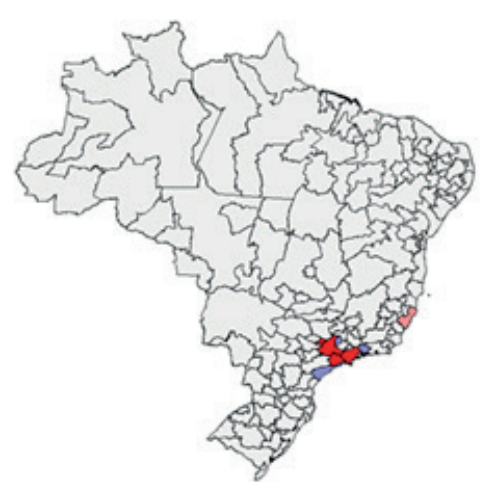

Subdominio 9

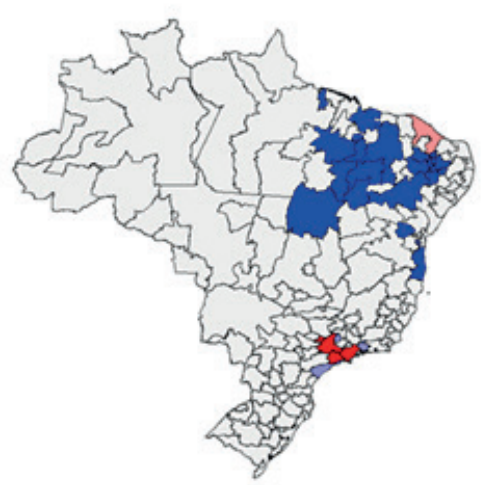

Subdominio 12

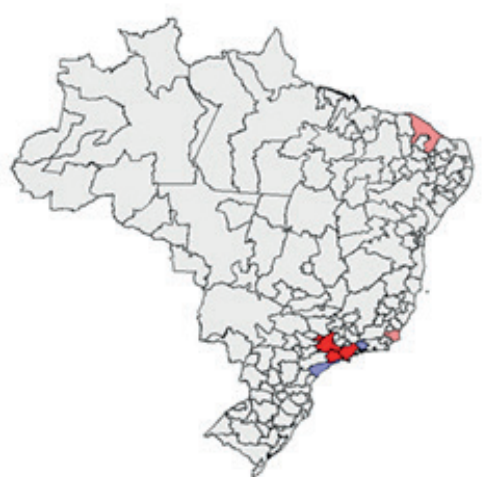

Subdominio 14
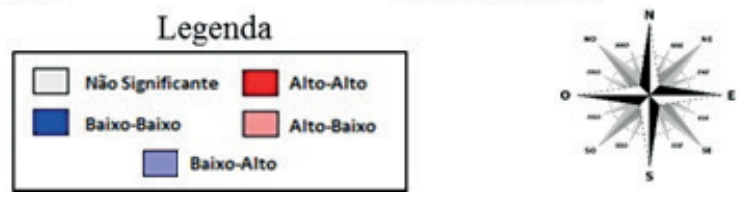


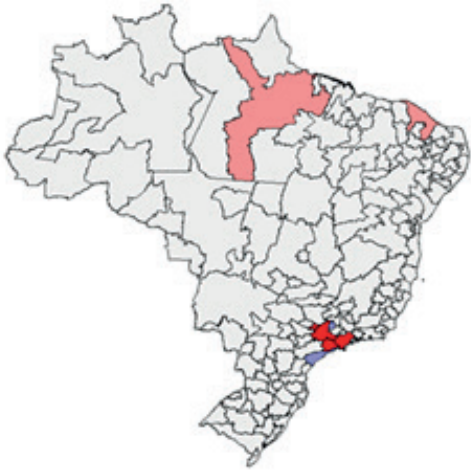

Subdominio 15

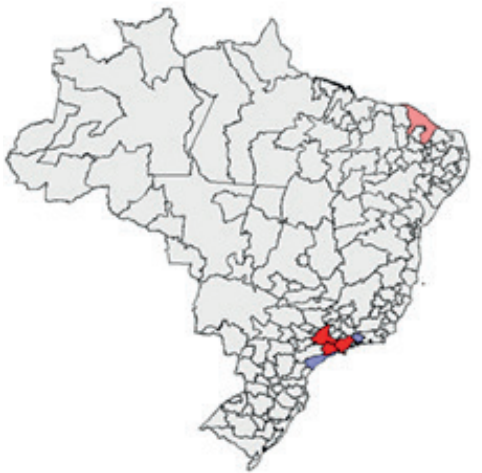

Subdomínio 17

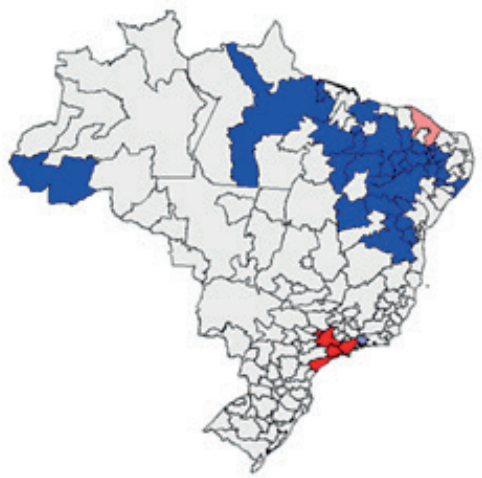

Subdominio 19

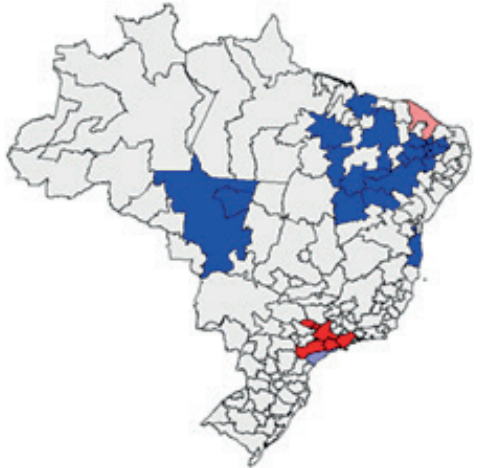

Subdominio 16

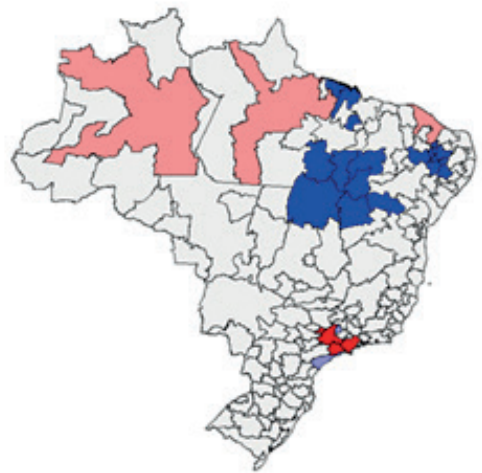

Subdomínio 18

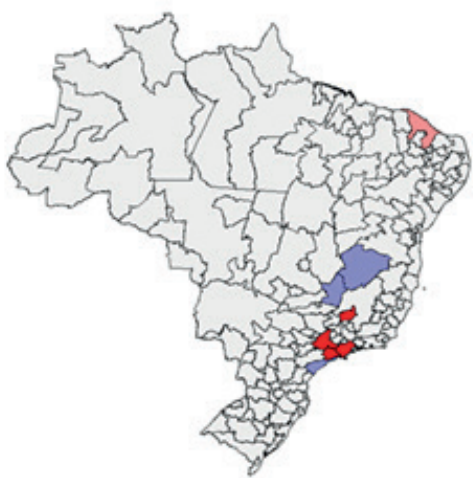

Subdominio 20

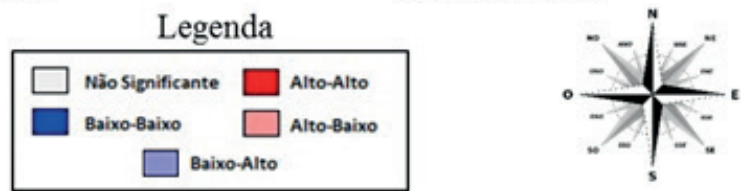




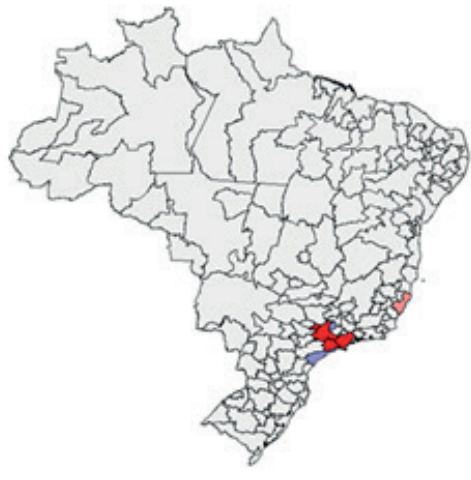

Subdominio 21

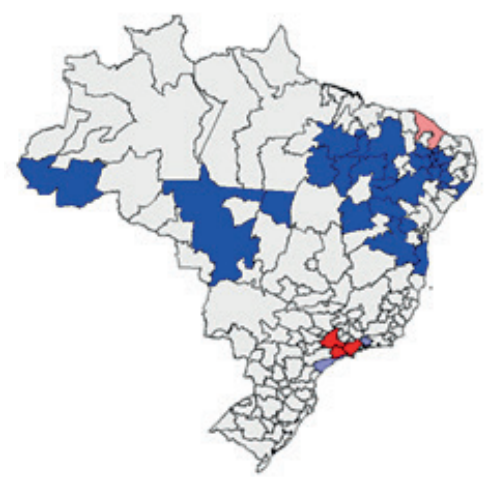

Subdominio 23 e 24

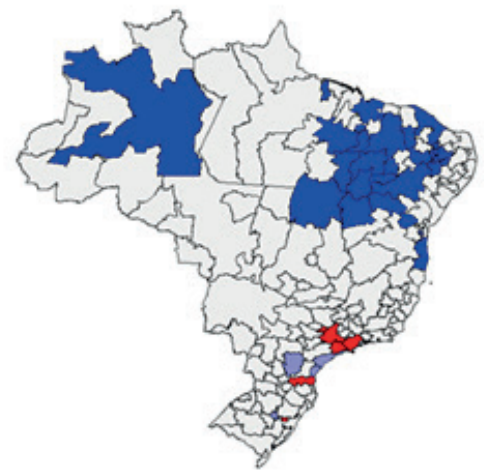

Subdominio 26

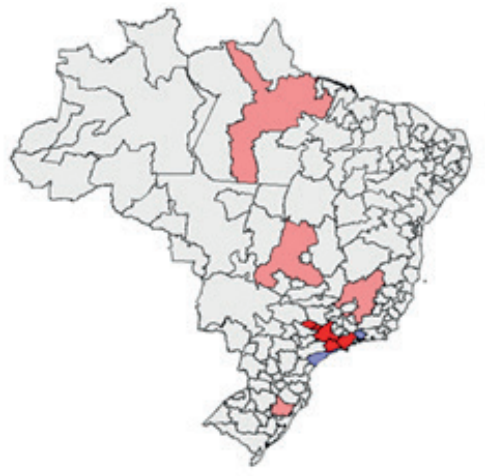

Subdominio 22

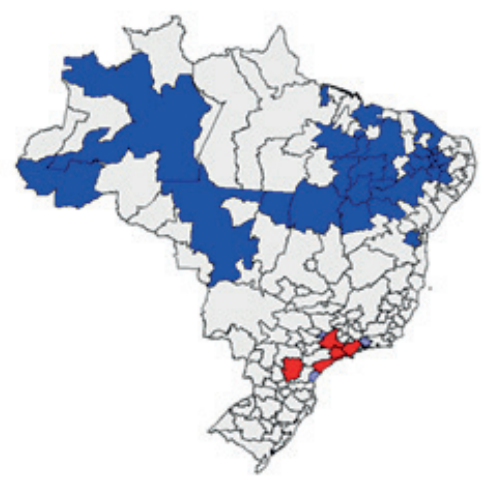

Subdomínio 25

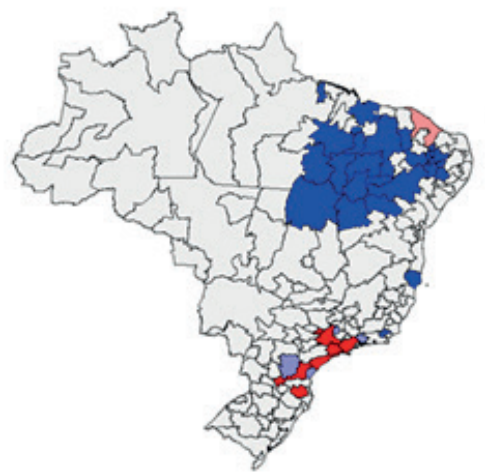

Subdomínio 27

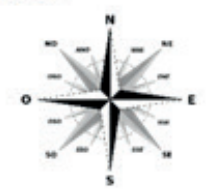




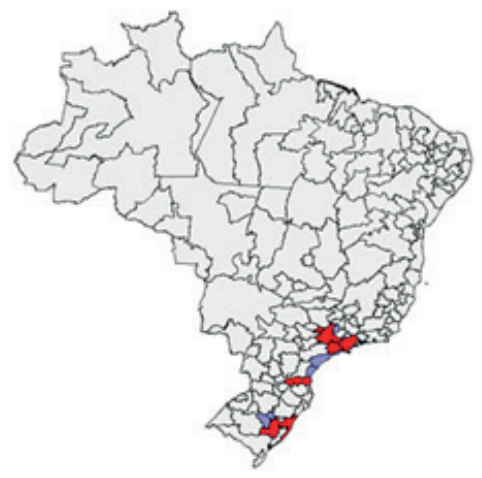

Subdominio 28

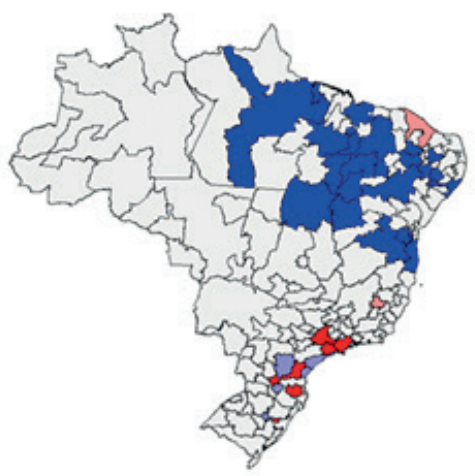

Subdomínio 30

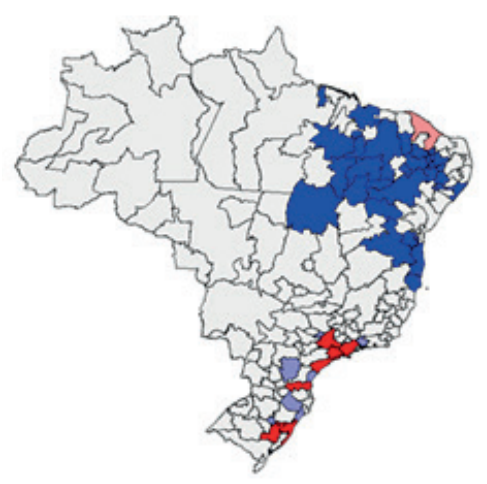

Subdominio 32

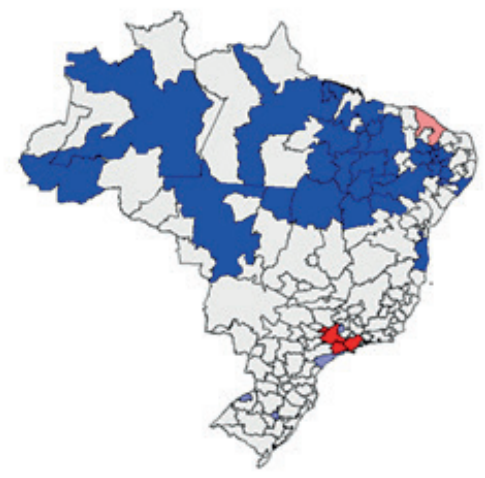

Subdominio 29

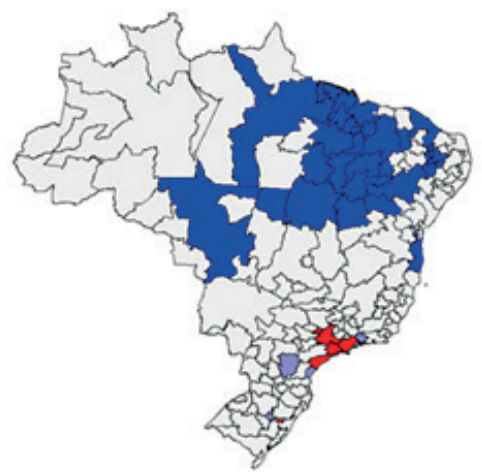

Subdominio 31

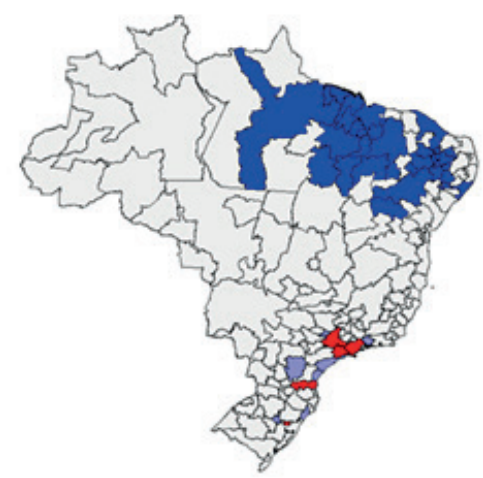

Subdominio 33

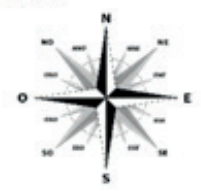




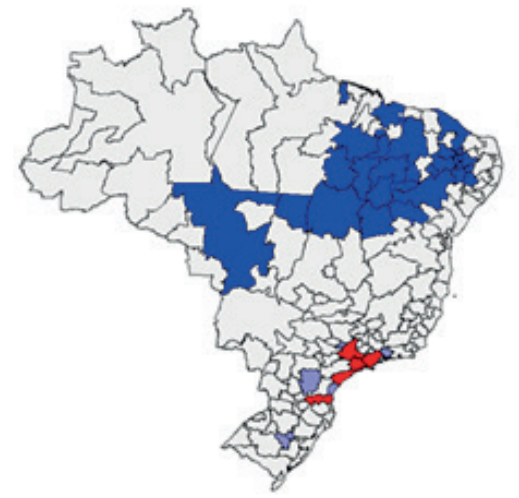

Subdomínio 34

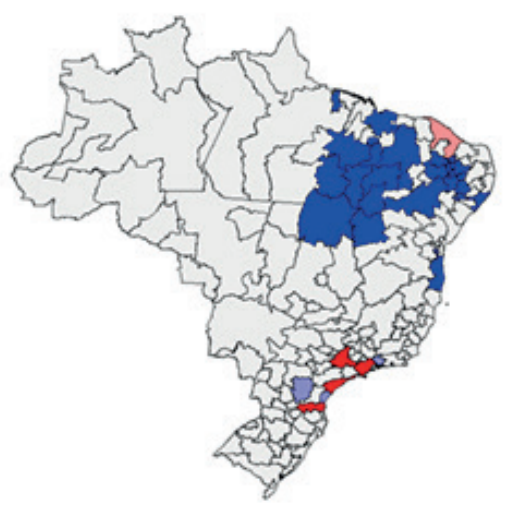

Subdomínio 35

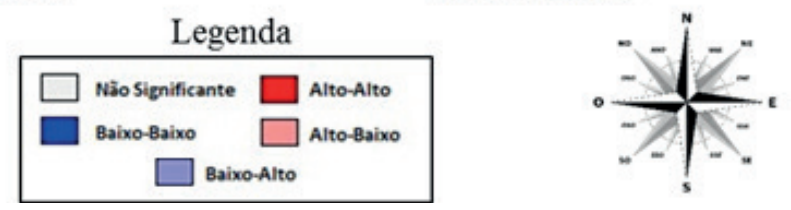

